San Jose State University

SJSU ScholarWorks

Master's Theses

Master's Theses and Graduate Research

Summer 2015

\title{
Effects of Particle Size and Particle Heterogeneity on Benthic Functional Guilds in Elkhorn Slough, CA
}

Katherine Elizabeth Huotari

San Jose State University

Follow this and additional works at: https://scholarworks.sjsu.edu/etd_theses

\section{Recommended Citation}

Huotari, Katherine Elizabeth, "Effects of Particle Size and Particle Heterogeneity on Benthic Functional Guilds in Elkhorn Slough, CA" (2015). Master's Theses. 4589.

DOI: https://doi.org/10.31979/etd.k6vh-9y5e

https://scholarworks.sjsu.edu/etd_theses/4589

This Thesis is brought to you for free and open access by the Master's Theses and Graduate Research at SJSU ScholarWorks. It has been accepted for inclusion in Master's Theses by an authorized administrator of SJSU ScholarWorks. For more information, please contact scholarworks@sjsu.edu. 


\title{
EFFECTS OF PARTICLE SIZE AND PARTICLE HETEROGENEITY ON BENTHIC
} FUNCTIONAL GUILDS IN ELKHORN SLOUGH, CA

\author{
A Thesis \\ Presented to \\ The Faculty of the Department of Biological Sciences \\ San José State University \\ In Partial Fulfillment \\ of the Requirements for the Degree \\ Master of Science
}

by

Katherine E. Huotari

August 2015 
(C) 2015

Katherine E. Huotari

ALL RIGHTS RESERVED 
The Designated Thesis Committee Approves the Thesis Titled

EFFECTS OF PARTICLE SIZE AND PARTICLE HETEROGENEITY ON BENTHIC FUNCTIONAL GUILDS IN ELKHORN SLOUGH, CA

by

Katherine E. Huotari

APPROVED FOR THE DEPARTMENT OF BIOLOGICAL SCIENCES

SAN JOSÉ STATE UNIVERSITY

August 2015

Dr. Shannon Bros-Seemann

Department of Biological Sciences

Dr. John Oliver

Moss Landing Marine Laboratories

Dr. Stacy Kim

Moss Landing Marine Laboratories 


\begin{abstract}
EFFECTS OF PARTICLE SIZE AND PARTICLE HETEROGENEITY ON BENTHIC FUNCTIONAL GUILDS IN ELKHORN SLOUGH, CA
\end{abstract}

by Katherine E. Huotari

Changes in particle size of sediment as a result of erosion can have potential impacts on benthic community structure. To examine the potential impacts, a $2 \times 2$ factorial design was used to evaluate the effects of particle size and particle heterogeneity on the intertidal community structure of Elkhorn Slough using data provided by Moss Landing Marine Laboratories. In this study, changes in functional guild roles with respect to particle size and particle heterogeneity were examined, rather than traditional biological measures, because functional guild roles are more directly related to physical changes in the environment. The results showed that particle size and particle heterogeneity affected functional roles. Increases in particle size showed a corresponding decrease in number of surface-dwelling species and of surface and subsurface individuals. In addition, increases were observed in the number of domicile guilds, tubedwelling species, suspension species, deposit-feeding species, and deposit-feeding individuals. Decreases in particle heterogeneity corresponded with a decrease in the number of feeding guilds. This research indicates that the benthic community in Elkhorn Slough may change radically over time, particularly in response to changes in particle size. 


\section{ACKNOWLEDGEMENTS}

I would first like to express my gratitude towards my committee members: Dr. Shannon Bros-Seemann, Dr. John Oliver, and Dr. Stacy Kim. Shannon, you have impacted my life in the last three years more ways than I can describe. Not only have you been a role model as a scientist and educator, but you have been a dear friend. I am forever grateful to you. John and Stacy, thank you so much for your enduring patience and support. You have made me a better scientist, and person. Kamille Hammerstrom and Peter Slattery have generously volunteered their time with me due to their deep love of the slough and have therefore also been key contributors to the success of this project.

To my family, I would like to thank you for support. If it weren't for your encouragement, I would not have achieved this degree let alone dared venture into science. You are responsible for teaching me my science mantra, "Test everything. Hold on to the good". Thank you for staying grounded, and always offering guidance.

I would finally like to thank my husband, Dan Dockendorf. You are the person who needs the most thanks, yet it is impossible to capture in text how grateful I am for you. You have been by my side for every moment in this journey, seeing every high and low. It takes a person with enormous strength to stay positive for me every day, and I would be lost without you. Thank you for being someone I can laugh with, and cry with, freely, and for making sure we mostly laugh. 


\section{Table of Contents}

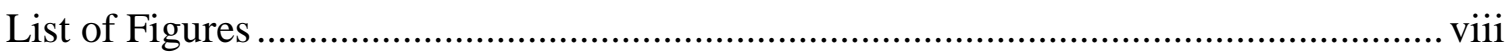

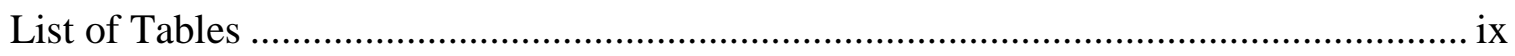

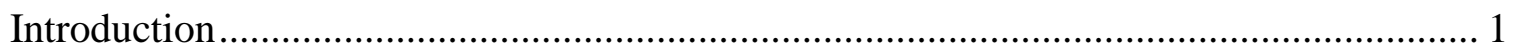

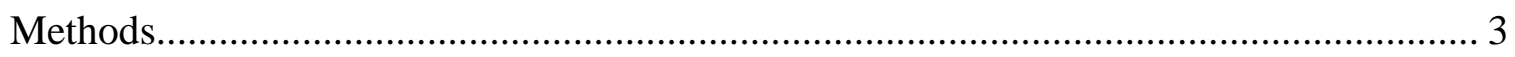

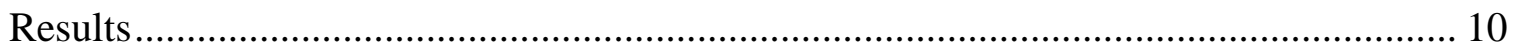

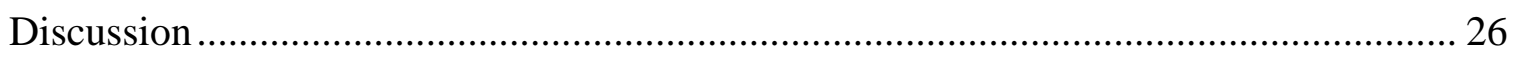

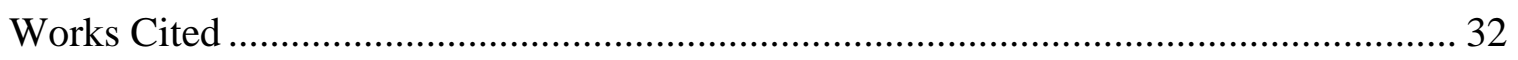

APPENDIX A: The mean particle size (Size) and mean geometric standard deviation (Std. Dev.), aka particle heterogeneity, for forty Elkhorn Slough stations from the 2007 survey. Data provided by the Geological Oceanography Lab at Moss Landing Marine

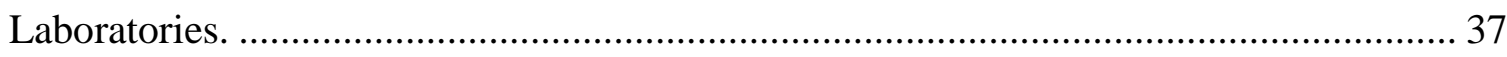

APPENDIX B: List of Elkhorn Slough intertidal benthic species (A-E) and their corresponding functional guild assignments according to Macdonald et al. (2010)....... 38

APPENDIX C: List of Elkhorn Slough intertidal benthic species (G-M) and their corresponding functional guild assignments according to Macdonald et al. (2010)....... 39

APPENDIX D: List of Elkhorn Slough intertidal benthic species (N-R) and their corresponding functional guild assignments according to Macdonald et al. (2010)....... 40

APPENDIX E: List of Elkhorn Slough intertidal benthic species (S-Z) and their corresponding functional guild assignments according to Macdonald et al. (2010). 41

APPENDIX F: List of Elkhorn Slough intertidal benthic species (A-E) and their corresponding guild assignments according to the five two-guild classification schemes.

APPENDIX G: List of Elkhorn Slough intertidal benthic species (G-M) and their corresponding guild assignments according to the five two-guild classification schemes.

APPENDIX H: List of Elkhorn Slough intertidal benthic species (N-R) and their corresponding guild assignments according to the five two-guild classification schemes. 
APPENDIX I: List of Elkhorn Slough intertidal benthic species (S-Z) and their corresponding guild assignments according to the five two-guild classification schemes.

APPENDIX J: Frequency of species' occurrences within the benthic invertebrate tubebuilding and burrowing domicile guilds between particle size treatments (small: $\leq 18.1$ $\mu \mathrm{m}$; large: > $18.1 \mu \mathrm{m}$ ) among all Elkhorn Slough Stations.

APPENDIX K: The number of species within the sixteen Elkhorn Slough benthic invertebrate feeding guilds among the particle heterogeneity treatments. 46 


\section{List of Figures}

Figure 1: The location of Elkhorn Slough, California. Figure adapted from Moss Landing Marine Laboratories. Symbols represent the sediment particle treatments.

Figure 2: Significant particle size effect from a three-way ANOVA with independent variables: particle size (levels: small, large), and particle heterogeneity (levels: low, high), and location guild (subsurface, surface)

Figure 3: Significant particle size effect from a three-way ANOVA with independent variables: particle size (levels: small, large), and particle heterogeneity (levels: low, high), and location guild (subsurface, surface)

Figure 4: Significant ( $p=0.002)$ particle size effect from a two-way ANOVA with independent variables: particle size (levels: low, high), and particle heterogeneity (levels: low, high)

Figure 5: Significant particle size effect from a three-way ANOVA with independent variables: particle size (levels: small, large), and particle heterogeneity (levels: low, high), and domicile guild (non-tube dwelling, tube-dwelling)

Figure 6: Significant ( $p=0.015)$ particle heterogeneity effect from a two-way ANOVA with independent variables: particle size (levels: small, large), and particle heterogeneity (levels: low, high)

Figure 7: Significant particle size effect from a three-way ANOVA with independent variables: particle size (levels: small, large), and particle heterogeneity (levels: low, high), and feeding guild (non-suspension, suspension)

Figure 8: Significant particle size effect from a three-way ANOVA with independent variables: particle size (levels: small, large), and particle heterogeneity (levels: low, high), and feeding guild (non-deposit, deposit)

Figure 9: Significant particle size effect from a three-way ANOVA with independent variables: particle size (levels: small, large), and particle heterogeneity (levels: low, high), and feeding guild (non-deposit, deposit) 


\section{List of Tables}

Table 1: The $2 \times 2$ factorial design of particle size and particle heterogeneity within forty Elkhorn Slough stations

Table 2: Two-Way ANOVAs of the effects of particle size (levels: small, large) and particle heterogeneity (levels: low, high) on the species-based richness and evenness of invertebrate benthic motility guilds in Elkhorn Slough

Table 3: Three-way ANOVAs of the effects of particle size (levels: small, large) and particle heterogeneity (levels: low, high) on invertebrate benthic functional motility guilds (motile, sessile) in Elkhorn Slough for (A) the proportion of possible number of species in motile or sessile guilds or (B) the rank number of individuals in motile or sessile guilds

Table 4: Three-way ANOVAs of the effects of particle size (levels: small, large) and particle heterogeneity (levels: low, high) on invertebrate benthic functional location guilds (surface, subsurface) in Elkhorn Slough for (A) the proportion of possible number of species in surface or subsurface guilds or (B) the rank number of individuals in surface or subsurface guilds.

Table 5: Two-Way ANOVAs of the effects of particle size (levels: small, large) and particle heterogeneity (levels: low, high) on the species-based richness and evenness of invertebrate benthic domicile guilds in Elkhorn Slough.

Table 6: Three-way ANOVAs of the effects of particle size (levels: small, large) and particle heterogeneity (levels: low, high) on invertebrate benthic functional domicile guilds (tube dwelling, non-tube dwelling) in Elkhorn Slough for (A) the proportion of possible number of species in tube dwelling or non-tube dwelling guilds or (B) the rank number of individuals in tube dwelling or non-tube dwelling guilds....

Table 7: Two-Way ANOVAs of the effects of particle size (levels: small, large) and particle heterogeneity (levels: low, high) on the species-based richness and evenness of invertebrate benthic feeding guilds in Elkhorn Slough.

Table 8: Three-way ANOVAs of the effects of particle size (levels: small, large) and particle heterogeneity (levels: low, high) on invertebrate benthic functional feeding guilds (suspension, non-suspension) in Elkhorn Slough for (A) the proportion of possible number of species in suspension or non-suspension guilds or (B) the rank number of individuals in suspension or non-suspension guilds 
Table 9: Three-way ANOVAs of the effects of particle size (levels: small, large) and particle heterogeneity (levels: low, high) on invertebrate benthic functional feeding guilds (deposit, non-deposit) in Elkhorn Slough for (A) the proportion of possible number of species in deposit or non-deposit guilds or (B) the rank number of individuals in deposit

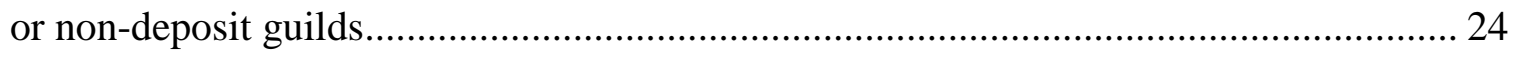




\section{Introduction}

Ecological communities are inherently shaped by interactions between physical and biological processes (Sebens, 1991), and physical characteristics of sediment, such as particle size and/or particle heterogeneity, have profound effects on benthic communities. The hypothesized relationship between particle size and community structure is that smaller sediment grain sizes results in more homogenous benthic communities (Davis, 1980; Riddle, 1988; Ellingsen, 2002; Downes, Lake, Glaister, \& Bond, 2006; Vanaverbeke, Mercx, Degraer, \& Vincx, 2011). For benthic studies, sediment heterogeneity can be used as a measure of habitat complexity (Gray, 1981; Blott \& Pye, 2001). High complexity is thought to facilitate complex community structure (Simpson, 1964; Huston, 1979; Johnson, 1970; Downes, Lake, Schreiber, \& Glaister, 1998). This positive relationship has been demonstrated in a multitude of habitats including the deep sea, freshwater rivers, and floodplains (Etter \& Grassle, 1992; Zilli, Montalto, \& Marchese, 2008; Wyzga, Oglecki, Radecki-Pawlik, Skalski, \& Zawiejska, 2011). Species diversity and species composition are often used as primary measures of community structure. These measures are useful but do not directly address ecological roles. Indices are useful but not always interpretable; for example, because the Shannon Weiner diversity measure ( $\left.\mathrm{H}^{\prime}\right)$ blends both evenness and richness, the interpretation of an $\mathrm{H}^{\prime}$ value is not readily apparent. For any given $\mathrm{H}^{\prime}$ value, it is generally necessary to examine the values of richness (simply the number of species) and evenness (H'/Maximum H') for interpretation. Species composition is also problematic because it addresses only the identity of species and not their ecological roles. For example, it is 
much more ecologically relevant to find that sediment characteristics affect the distribution of functional groups, such as tube-dwelling species, because they are capable of altering the benthic environment (Fager, 1964). Measures that are inherently ecological in nature should lend themselves to more direct ecological-based conclusions. Species can instead be assessed ecologically by categorizing them into functional guilds; some examples of functional guilds include method of feeding, degree of motility, and type of domicile (e.g. tube-dwelling).

Elkhorn Slough provides a venue to examine the effect of sediment characteristics (particle size and particle heterogeneity) on benthic communities. Elkhorn Slough is an $11 \mathrm{~km}$-long marine embayment located in Monterey Bay in Monterey County, California. The homogeneity of Elkhorn Slough's water chemistry parameters makes it an ideal location to conduct a study that focuses on the effects of physical habitat characteristics (sediment particle size and particle heterogeneity) on benthos. In Elkhorn Slough, the range of particle size and particle heterogeneity is limited; however, it is possible to create a natural factorial experiment within those ranges to determine if particle size, particle heterogeneity, or the interaction between those factors affects community structure. Finally, Moss Landing Marine Laboratories sampled the benthic intertidal macrofauna and sediment in 2003 and 2007, respectively, and made the data available for analysis.

Elkhorn Slough can also be used to study effects of sediment characteristics in both the short and long term. In 1947 the Moss Landing Harbor, located at the mouth of Elkhorn Slough, was widened for increased boat traffic. The modification exposed the 
slough to severe tidal erosion forces (Crampton, 1994). Since then, the sediment composition has become more homogenous, and dominated by larger particle sizes (Philip Williams \& Associates Ltd., 1992; Malzonen, 1999). The qualitative comparison between benthic community structures in the 1970s and in 2003, performed by Oliver, Hammerstrom, Kim, Slattery, Oakden, Kvitek, and Aiello (2007), may coincide with community-habitat relationships found in this study.

There were three goals of this research. The first was to utilize a natural experiment to determine if the sediment characteristics (particle size and particle heterogeneity) of Elkhorn Slough affect the population and community structures of benthic intertidal invertebrates. The second was to determine if the relationships between functional community structure and sediment characteristics possess long-term constancy by comparing the current community patterns to those from the 1970s. The third and was to predict, with a sufficient amount of power, how future changes in sediment characteristics via erosion may impact the community dynamics of Elkhorn Slough benthos.

\section{Methods}

Benthic invertebrate species data from a 2003 Elkhorn Slough survey report (Oliver et al. 2007) were provided by the Benthic Ecology lab at Moss Landing Marine Laboratories. Data were collected for that survey via benthic cores $\left(0.0078 \mathrm{~m}^{2}, 10-12 \mathrm{~cm}\right.$ in the sediment) at 40 intertidal stations distributed throughout the entirety of the slough (Figure 1). Species abundance data were collected from each of 40 cores; the methodology for collecting and processing samples was described in detail in the report. 


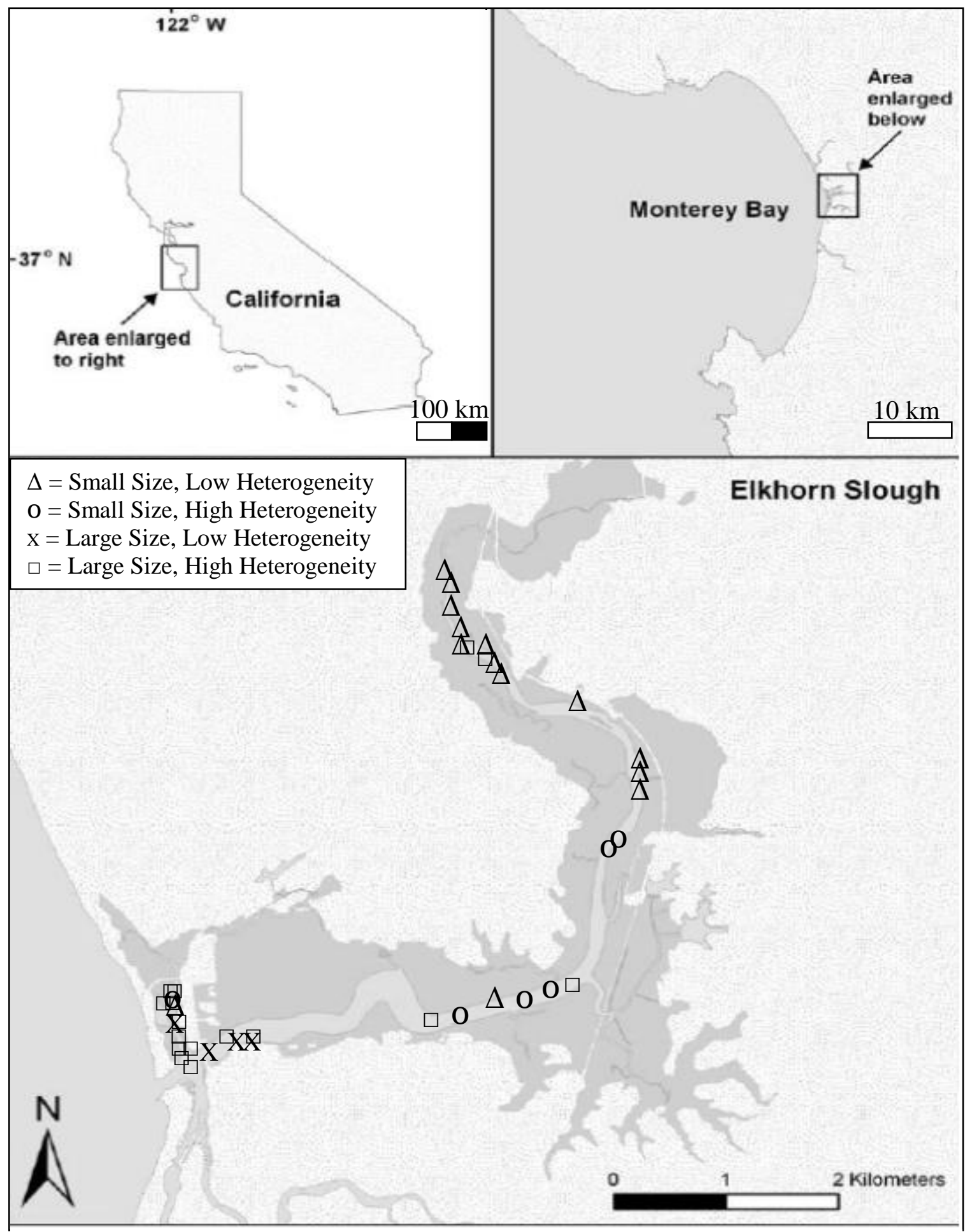

Figure 1: The location of Elkhorn Slough, California. Figure adapted from Moss Landing Marine Laboratories. Symbols represent the sediment particle treatments. 
Data provided by the Geological Oceanography Lab at Moss Landing Marine Laboratories analysis (Oliver et al. 2007) were used to assess and categorize the particle size and particle heterogeneity at each station. Sediment cores $(3 \mathrm{~cm}$ diameter, $10-20 \mathrm{~cm}$ depth) in the 2007 study were collected from the same stations as in the 2003 species survey. Grain size distribution was measured with $1 \mathrm{~cm}$ subsamples cut vertically from cores. Data provided included mean grain size and geometric standard deviation of grain size for each station. Blott and Pye (2001) suggested that an appropriate measure of particle size heterogeneity is the standard deviation of the particle size sample distribution. A sediment sample with a large standard deviation of grain size would be considered less sorted and, therefore, more heterogeneous.

Ideally, sediment data should have been collected at the same time as in the benthic survey, but that was not the case. During the 4 years that passed between the benthic survey and the sediment survey, sediment characteristics changed via erosion; throughout most of the slough, particle size increased and heterogeneity decreased (Philip Williams \& Associates Ltd., 1992; Malzonen 1999; Oliver et al., 2007). Therefore, any observed community changes in the 2003 data with respect to particle size and particle heterogeneity would be a function of particles that were been smaller and more heterogeneous than in 2007. However, relative differences in measured variables with respect to particle size and particle heterogeneity on benthic functional groups would still indicate effects of these factors.

A $2 \times 2$ factorial design was used to evaluate the effects of particle size, particle heterogeneity and the potential interaction between particle size and particle 
heterogeneity on the intertidal community structure of Elkhorn Slough. Traditional sediment groupings of particle size (gravel, sand, etc.) could not be used because they encompass a greater range of particle sizes than was available. In addition, particle sizes throughout Elkhorn Slough were skewed towards small sizes. Because of these factors, stations were assigned to only two categories based on particle size. This type of grouping has low resolution that allows a relative evaluation of the effects of size and heterogeneity on community functional structure. Two categories were constructed for particle size based on the median particle size of all stations $(18.1 \mu \mathrm{m})$ : small $(\leq 18.1 \mu \mathrm{m})$ and large $(>18.1 \mu \mathrm{m})$. The same method of median-based classification was used to classify stations into low $(\leq 4.175 \mu \mathrm{m})$ and high particle heterogeneity $(>4.175 \mu \mathrm{m})$ given a median measure of heterogeneity $(4.175 \mu \mathrm{m})$. The geometric standard deviation of particle size was used as the measure of particle heterogeneity. The final numbers of stations in each treatment combination are illustrated in Table 1, and the distribution of the stations is illustrated in Figure 1. The specific mean particle size and particle standard deviation (particle heterogeneity) for each station are included in Appendix A. Four combinations based on median groupings allowed a relatively balanced $2 \times 2$ factorial design: small particle size and low particle heterogeneity, small particle size and high particle heterogeneity, large particle size and low particle heterogeneity, and large particle size and high particle heterogeneity. 
Table 1: The 2x2 factorial design of particle size and particle heterogeneity within forty Elkhorn Slough stations.

\begin{tabular}{ccccc} 
& & \multicolumn{2}{c}{ Mean Particle Size } & \\
& & $\begin{array}{c}\text { Small } \\
(\leq 18.1 \mu \mathrm{m})\end{array}$ & $\begin{array}{c}\text { Large } \\
(>18.1 \mu \mathrm{m})\end{array}$ & Total \\
\hline \multirow{2}{*}{$\begin{array}{c}\text { Particle } \\
\text { Heterogeneity }\end{array}$} & Low & & & \\
\cline { 2 - 5 } & $(\leq 4.175$ St. Dev. $)$ & 14 & 4 & 18 \\
\cline { 2 - 5 } & High & 6 & 16 & 22 \\
\cline { 2 - 5 } & $(>4.175$ St. Dev. $)$ & 20 & 20 & 40
\end{tabular}

Guild richness was used a measure of the diversity of functional roles in the community. Species were classified into guild types based on the classification scheme of MacDonald, Burd, MacDonald, and van Roodselaar (2010), and then the numbers of guild types were enumerated for each station. Motility guilds (referred to in Macdonald et al., 2010, as life habit) were based on the degree and purpose of the organism's movement/activity. Species were categorized as completely sessile (S); is able to move, but movement isn't necessary for feeding (discretely motile, D); or moves actively, and movement is required for feeding (motile, M). Domicile guilds were based on living situation. A species may be free-living (may live on surface or actively burrow, F), tubedwelling (T), burrow-dwelling (sedentary, living in burrow, B), or attached (to hard substrate by one or more points, A). Species were assigned to feeding guilds on the basis of four criteria: food source, diet, food type/size, and feeding mode. Food source of slough species fell into one of the following categories: epibenthic (EP), surface (SR), and subsurface (SS). Diet was defined by one of the following: carnivorous $(\mathrm{Ca})$, herbivorous (He), and omnivorous (Om). Food type/size of slough species were described as sediment (sed), benthic microfauna (single-celled organisms, mic), benthic 
meiofauna $(<500 \mu \mathrm{m}$, mei), and benthic macrofauna $(>500 \mu \mathrm{m}$, including macroalgae, mac). The fourth criteria, feeding mode, included Deposit feeder (ingests sediment, De), Detritus feeder (ingests matter without sediment, Dt), Suspension/Filter feeder (strains particles from the water, Su), Predator (eats live animals only, Pr), Scavenger (carrion only, Sc), and Chemosynthetic (with symbiotic bacteria, Ch). Using the MacDonald classification scheme, the seventy-five intertidal benthic species documented in the 2003 Elkhorn Slough survey were assigned to sixteen unique feeding guilds. If a slough species was not listed in Macdonald et al. (2010), then the next highest taxonomic level in common was used, without ever surpassing the family taxa. The functional guild assignments for each of the seventy-five slough species are illustrated in Appendices BE.

For each of the three guild classifications (motility, domicile, feeding), a two-way analysis of variance (2-Way ANOVA) (Zar, 2010) was used to determine if the number of guilds differed with respect to particle size and/or particle heterogeneity. The number of guilds was used as the dependent variable. Particle size (small: $\leq 18.1 \mu \mathrm{m}$, large: $>18.1$ $\mu \mathrm{m})$ and particle heterogeneity (low: $\leq 4.175 \mu \mathrm{m}$, high: $>4.175 \mu \mathrm{m})$ were used as the independent variables. In all analyses, Levene's test of homogeneity of variance indicated that the assumption of equality of variance was valid, and therefore did not require transformations to the data.

Unfortunately, the number of guild types as defined by MacDonald et al. (2010) contained too many categories for more detailed analyses involving the number of species or number of individuals within guild types. In several cases, a guild type was 
represented by only one species. Therefore, for analysis guilds needed to be redefined with fewer possible categories. Five different guild classification schemes, each with only two categories of guild types, were developed for analyses: motile versus sessile, tube-dwelling versus non-tube dwelling, deposit feeders versus non-deposit feeders, suspension feeders versus non-suspension feeders and surface dwelling versus subsurface dwelling. The group classifications for all of the species are illustrated in Appendices FI.

To determine if particle size and particle heterogeneity affected the number of species within a classification (e.g. suspension feeder or non-suspension feeder), a threeway analysis of variance (3-Way ANOVA) (Zar, 2010) was used to analyze each of the five guild classification schemes. Because the possible number of species within a guild type differed (e.g. more deposit feeding species than non-deposit feeding species). The number of species observed within a guild type at a station was weighted by the total possible number of species within that guild type. For example assume that there were 12 deposit feeding species and 20 non-deposit feeding species in the slough. At one station we observed 3 deposit feeders and 10 non-deposit feeders. Therefor the value for deposit feeders would be $3 / 12$ or 0.25 and the value for non-deposit feeders would be 10/20 or 0.5 . The three independent variables were: particle size, particle heterogeneity and guild classification (e.g., deposit vs. non-deposit feeders). An important consideration is that biological interpretation is possible only for those terms in the model that are interactions that include the guild classification term (e.g. guild*particle size, guild*heterogeneity and guild*particle size*heterogeneity). For example, for the analysis 
of deposit feeders, a significant interaction between the guild term (e.g., deposit feeder and non-deposit feeder) and particle size would indicate that the proportion of species within the guild types varied with respect to particle size. Conversely, a significant guild term in an analysis of deposit feeders and non-deposit feeders would merely indicate that the proportions of species designated as deposit feeder differed from the proportion of species designated as non-deposit feeder. Likewise a particle size*particle heterogeneity interaction would merely indicate a disparity in classification in the four sediment treatment groups. Levene's test of homogeneity of variance indicated that the data needed to be converted to ranks to meet the assumption.

Separate analyses for each of the five guild classification schemes were conducted to determine if the number of individuals within a guild type varied with respect to particle size and/or particle heterogeneity. Each analysis consisted of a 3-way ANOVA with the same factors as the previous analysis. As in the previous analyses, interactions without the guild term do not have a clear biological interpretation with respect to the functional classification. For example, in analysis of deposit feeders versus non-deposit feeders, a significant particle size*particle heterogeneity interaction would mean only that the number of individuals differs among the four treatment combinations. The primary difference being that the data were not weighted. To meet the assumption of equality of variance, the numbers of individuals were converted to ranks.

\section{Results}

Particle characteristics had no effect on the abundance or distribution of motility guilds. A 2-way ANOVA showed that the number of motility guilds (motile, discretely 
motile, or sessile) did not differ with respect to particle characteristics (Table 2). The 3way ANOVA for examining the difference in proportion of sessile species to motile species (Table 3A) showed that, in Elkhorn Slough, there was no significant difference between the groups relating to particle size $(p=0.602)$, heterogeneity of particle size ( $p=$ $0.142)$ or both $(p=0.776)$. The 3-way ANOVA for examining differences in number of individuals between the motile and sessile groups (Table 3B) showed a similar result (particle size, $p=0.688$; heterogeneity $p=0.757$; particle size*heterogeneity $p=0.647$ ).

Table 2: Two-Way ANOVAs of the effects of particle size (levels: small, large) and particle heterogeneity (levels: low, high) on the species-based richness and evenness of invertebrate benthic motility guilds in Elkhorn Slough. Error $\mathrm{df}=36$ in all dependent variables. Numbers in parentheses beneath marginally non-significant results $(0.05 \leq p<0.10)$ indicate results from power analysis.

\section{Dependent= Motility Guild Richness}

\begin{tabular}{lccc} 
Source & df & F & $\boldsymbol{p}$ \\
\hline Particle Size & 1 & 0.004 & 0.952 \\
Particle Heterogeneity & 1 & 0.623 & 0.435 \\
Particle Size*Heterogeneity & 1 & 3.102 & 0.087 \\
& & & $(0.403)$
\end{tabular}


Table 3: Three-way ANOVAs of the effects of particle size (levels: small, large) and particle heterogeneity (levels: low, high) on invertebrate benthic functional motility guilds (motile, sessile) in Elkhorn Slough for (A) the proportion of possible number of species in motile or sessile guilds or (B) the rank number of individuals in motile or sessile guilds. Error $\mathrm{df}=72$. Terms not including the motility guild factor have no biological meaning for the analyses and have been excluded from this table.

\begin{tabular}{lccc} 
Source & df & F & $\boldsymbol{p}$ \\
\hline A) Dependent= Proportion of Species & & & \\
Particle Size*Motility Guild & 1 & 0.274 & 0.602 \\
Heterogeneity*Motility Guild & 1 & 2.203 & 0.142 \\
Particle Size*Heterogeneity*Motility Guild & 1 & 0.081 & 0.776 \\
& & & \\
B) Dependent= Number of Individuals & & & \\
Particle Size*Motility Guild & 1 & 0.162 & 0.688 \\
Heterogeneity*Motility Guild & 1 & 0.097 & 0.757 \\
Particle Size*Heterogeneity*Motility Guild & 1 & 0.212 & 0.647
\end{tabular}

The 3-way ANOVAs showed that location guilds (surface, subsurface) in Elkhorn Slough were affected by particle size. The significant $(p=0.007)$ Particle Size*Location Guild interaction in the ANOVA for examining the difference in proportion of surface species to subsurface species (Table 4A) showed that there was a greater proportion of subsurface-dwelling species when particle size was large, but a lesser number of surfacedwelling species, (Figure 2). The significant $(p=0.024)$ Particle Size*Location Guild interaction in the ANOVA (Table 4B) for examining differences in number of individuals between the surface and subsurface groups showed that, while both of the groups were less abundant in the larger particle size treatment, the degree of difference between the large and small particle size treatment was more pronounced with surface species (Figure $3)$. 
Table 4: Three-way ANOVAs of the effects of particle size (levels: small, large) and particle heterogeneity (levels: low, high) on invertebrate benthic functional location guilds (surface, subsurface) in Elkhorn Slough for (A) the proportion of possible number of species in surface or subsurface guilds or (B) the rank number of individuals in surface or subsurface guilds. Error $\mathrm{df}=72$. Terms not including the location guild factor have no biological meaning for the analyses and have been excluded from this table. Significant $(p<0.05)$ indicated in bold.

Source $\quad$ df

\section{A) Dependent $=$ Proportion of Species}

Particle Size*Location Guild

Heterogeneity*Location Guild

Particle Size*Heterogeneity*Location Guild

B) Dependent $=$ Number of Individuals

Particle Size*Location Guild

Heterogeneity*Location Guild

Particle Size*Heterogeneity*Location Guild

$\begin{array}{lll}1 & 7.780 & \mathbf{0 . 0 0 7} \\ 1 & 1.276 & 0.262 \\ 1 & 2.778 & 0.100\end{array}$

$1 \quad 5.312$

0.024

$1 \quad 0.731$

0.396

$1 \quad 0.288$

0.593 


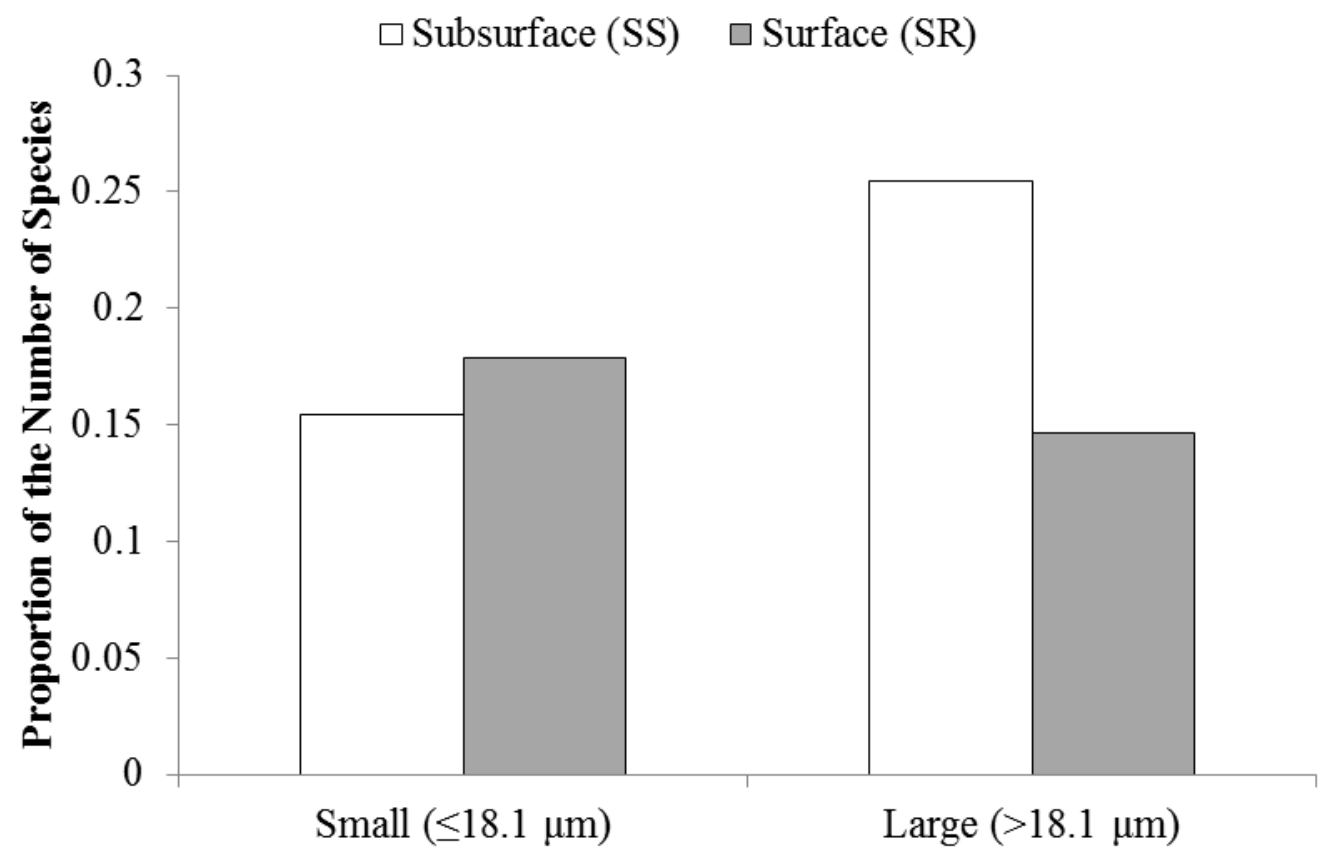

Particle Size Treatment

Figure 2: Significant particle size effect from a three-way ANOVA with independent variables: particle size (levels: small, large), and particle heterogeneity (levels: low, high), and location guild (subsurface, surface). Dependent variable is the proportion of species present within the benthic location guild assignment $(p=0.007)$ in Elkhorn Slough. Data were ranked for analysis and there are no appropriate confidence intervals for ranked data. 


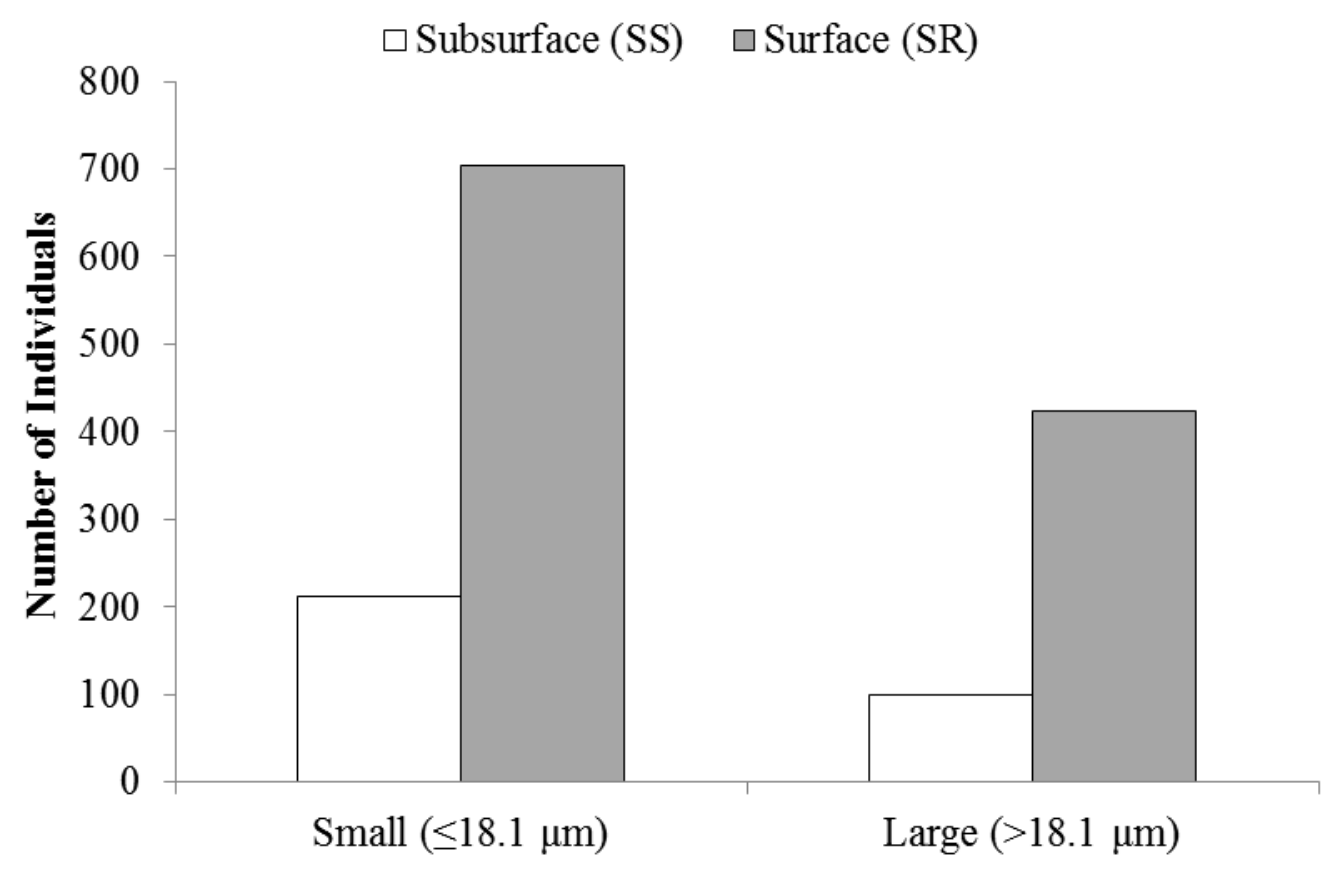

Particle Size Treatment

Figure 3: Significant particle size effect from a three-way ANOVA with independent variables: particle size (levels: small, large), and particle heterogeneity (levels: low, high), and location guild (subsurface, surface). Dependent variable is the number of individuals present within the benthic location guild assignment $(p=0.024)$ in Elkhorn Slough. Data were ranked for analysis and there are no appropriate confidence intervals for ranked data. 
Particle size was the only factor to have an effect on the abundance and distribution of species among domicile guilds. A 2-way ANOVA showed that the number of domicile guild types (tube-dwelling, burrowing, attached, and free-living) in Elkhorn Slough differed with respect to particle size (Table 5). There were significantly $(p=0.002)$ more domicile guild types when particle size was large (Figure 4$)$ which was a result of the burrowing guild's presence in the large particle size treatment only (Appendix I). The significant $(p=0.005)$ Particle Size*Domicile Guild interaction in the ANOVA (Table 6A) examining the difference in proportion of species within tubedwelling vs. non-tube dwelling showed the proportion of the number of tube-dwelling species was greatest in the small particle size treatments but the reverse was true for nontube dwelling species (Figure 5). However, when examining abundance with respect to tube-dwelling and non-tube dwelling species, there were no significant $(p>0.05)$ factors in the 3-way ANOVA (Table 6B).

Table 5: Two-Way ANOVAs of the effects of particle size (levels: small, large) and particle heterogeneity (levels: low, high) on the species-based richness and evenness of invertebrate benthic domicile guilds in Elkhorn Slough. Error df $=36$ in all dependent variables. Significant $(p<0.05)$ indicated in bold.

\section{Dependent $=$ Domicile Guild Richness}

\begin{tabular}{lccc} 
Source & df & F & $\boldsymbol{p}$ \\
\hline Particle Size & 1 & 11.639 & $\mathbf{0 . 0 0 2}$ \\
Particle Heterogeneity & 1 & 0.052 & 0.821 \\
Particle Size*Heterogeneity & 1 & 0.052 & 0.821
\end{tabular}




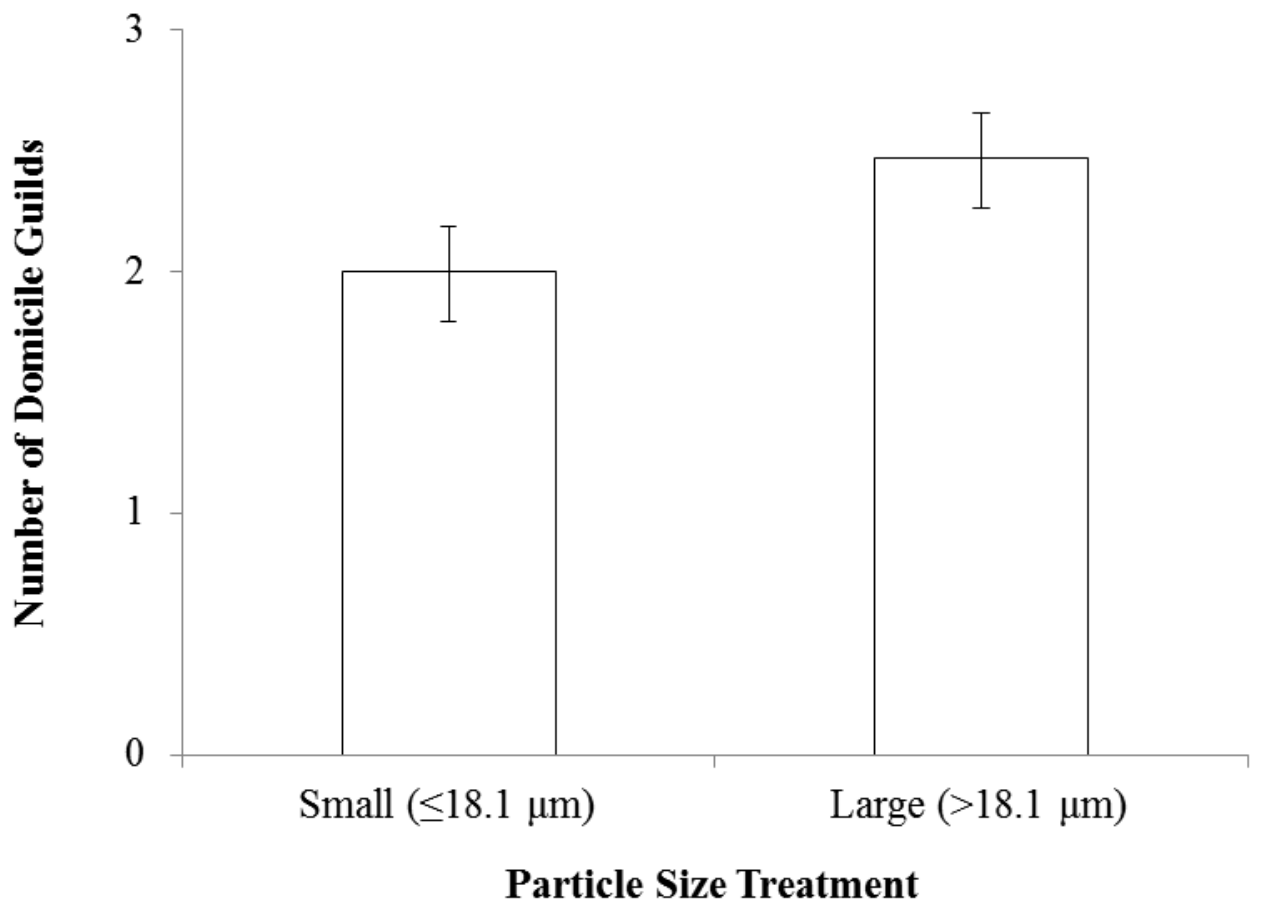

Figure 4: Significant $(p=0.002)$ particle size effect from a two-way ANOVA with independent variables: particle size (levels: low, high), and particle heterogeneity (levels: low, high). Dependent variable is the number of benthic invertebrate domicile guilds (richness) in Elkhorn Slough. Bars indicate 95\% confidence intervals. 
Table 6: Three-way ANOVAs of the effects of particle size (levels: small, large) and particle heterogeneity (levels: low, high) on invertebrate benthic functional domicile guilds (tube dwelling, non-tube dwelling) in Elkhorn Slough for (A) the proportion of possible number of species in tube dwelling or non-tube dwelling guilds or (B) the rank number of individuals in tube dwelling or non-tube dwelling guilds. Error $\mathrm{df}=72$. Terms not including the domicile guild factor have no biological meaning for the analyses and have been excluded from this table. Significant $(p<0.05)$ indicated in bold.

\begin{tabular}{llll} 
Source & df & F & $p$ \\
\hline
\end{tabular}

\section{A) Dependent $=$ Proportion of Species}

Particle Size*Domicile Guild

$1 \quad 8.589$

0.005

Heterogeneity*Domicile Guild

Particle Size*Heterogeneity*Domicile Guild

$1 \quad 2.056$

0.156

0.942

0.335

\section{B) Dependent $=$ Number of Individuals}

Particle Size*Domicile Guild

Heterogeneity*Domicile Guild

$1 \quad 0.803$

0.373

Particle Size*Heterogeneity*Domicile Guild

10.008

0.928

1

0.005

0.942 


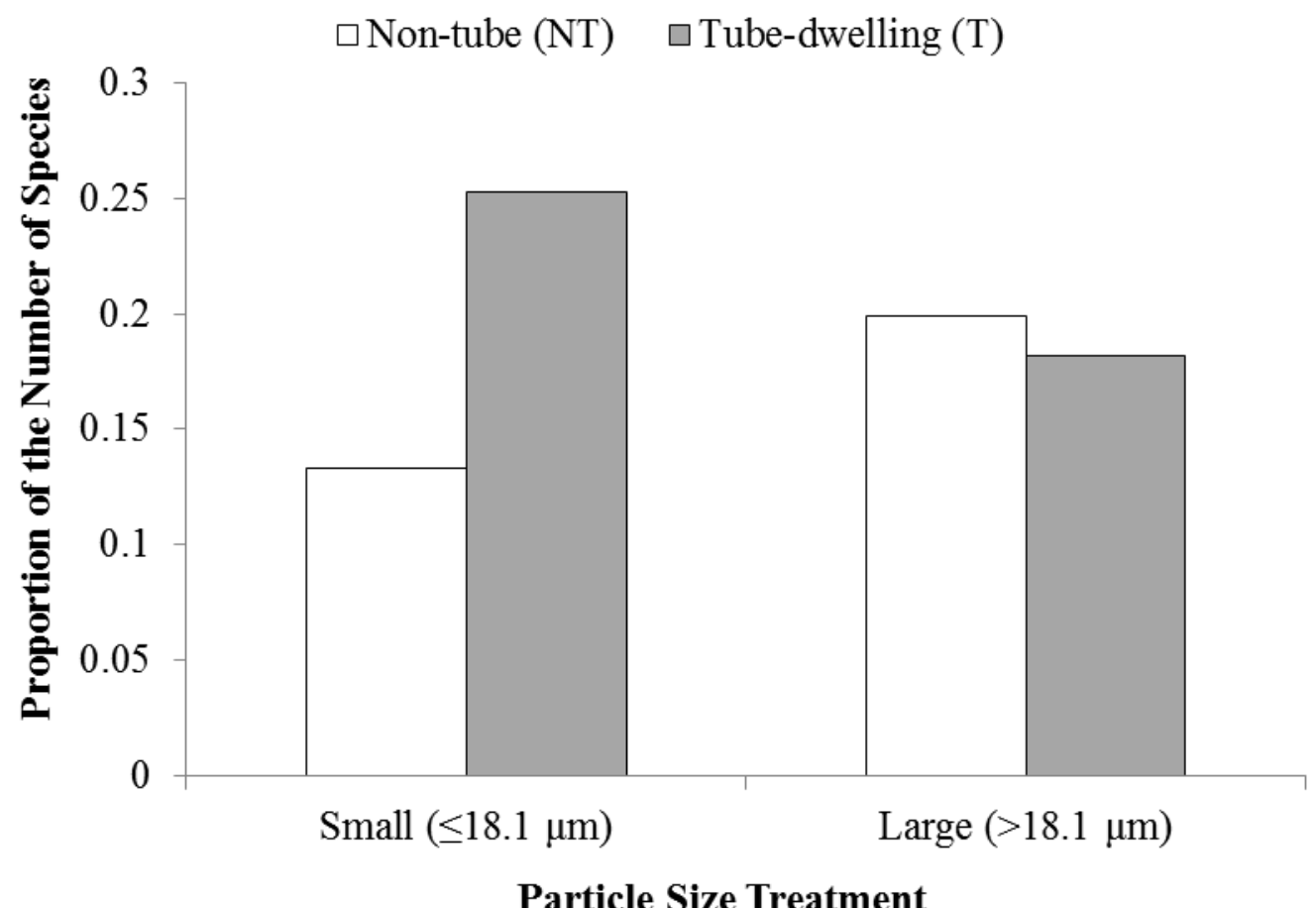

Figure 5: Significant particle size effect from a three-way ANOVA with independent variables: particle size (levels: small, large), and particle heterogeneity (levels: low, high), and domicile guild (non-tube dwelling, tubedwelling). Dependent variable is the proportion of species present within the benthic domicile guild assignment $(p=0.005)$ in Elkhorn Slough. Data were ranked for analysis and there are no appropriate confidence intervals for ranked data.

Both particle size and particle heterogeneity affected feeding guilds in different aspects. The 2-way ANOVA showed that the number of feeding guilds differed with respect to particle heterogeneity (Table 7). There were less feeding guilds when particle heterogeneity was low (Figure 6) which was a result of a loss in representation of three guilds; the surface-chemosynthetic-omnivore, surface-predatory-meiofauna and surfacescavenger-macrofauna guilds were not present when particle heterogeneity was low (Appendix J). The 3-way ANOVA for examining the difference in proportion of 
suspension species to non-suspension species (Table 8A) showed that, in Elkhorn Slough, there was a greater number of suspension feeding species when particle size was large ( $p=0.006$, Figure 7). The 3-way ANOVA for examining differences in number of individuals between the suspension and non-suspension groups (Table 8B) showed that in Elkhorn Slough, groups did not differ with respect to particle characteristics (particle size, $p=0.100$; heterogeneity $p=0.146$; particle size* heterogeneity $p=0.909)$. The 3 way ANOVA for examining the difference in proportion of deposit species to nondeposit species (Table 9A) showed that, in Elkhorn Slough, there was a greater number of deposit feeding species when particle size was large ( $p=0.002$, Figure 8$)$. The 3 -way ANOVA for examining differences in number of individuals between the deposit and non-deposit groups (Table 9B) showed that in Elkhorn Slough, there was a greater number of deposit feeding individuals, and a corresponding decrease in the number of non-deposit feeding individuals when particle size was large $(p=0.001$, Figure 9$)$.

Table 7: Two-Way ANOVAs of the effects of particle size (levels: small, large) and particle heterogeneity (levels: low, high) on the species-based richness and evenness of invertebrate benthic feeding guilds in Elkhorn Slough. Error $\mathrm{df}=36$ in all dependent variables. Significant $(p<0.05)$ indicated in bold.

\section{Dependent $=$ Feeding Guild Richness}

\begin{tabular}{lccc} 
Source & df & F & $\boldsymbol{p}$ \\
\hline Particle Size & 1 & 2.010 & 0.165 \\
Particle Heterogeneity & 1 & 6.475 & $\mathbf{0 . 0 1 5}$ \\
Particle Size*Heterogeneity & 1 & 0.293 & 0.591
\end{tabular}




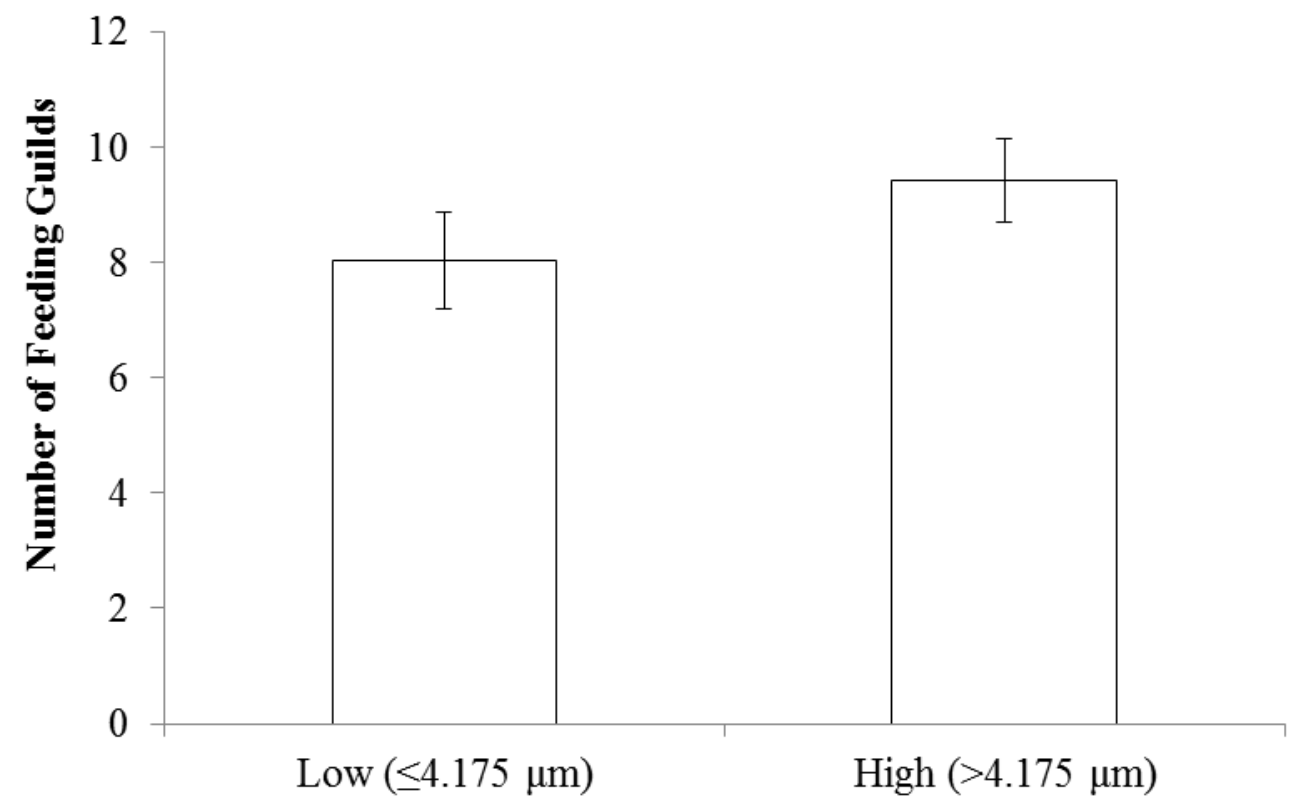

Particle Heterogeneity Treatment

Figure 6: Significant $(p=0.015)$ particle heterogeneity effect from a two-way ANOVA with independent variables: particle size (levels: small, large), and particle heterogeneity (levels: low, high); dependent variable is number of benthic invertebrate feeding guilds (richness) in Elkhorn Slough. Bars indicate $95 \%$ confidence intervals. 
Table 8: Three-way ANOVAs of the effects of particle size (levels: small, large) and particle heterogeneity (levels: low, high) on invertebrate benthic functional feeding guilds (suspension, non-suspension) in Elkhorn Slough for (A) the proportion of possible number of species in suspension or non-suspension guilds or (B) the rank number of individuals in suspension or non-suspension guilds. Error $\mathrm{df}=72$. Terms not including the feeding guild factor have no biological meaning for the analyses and have been excluded from this table. Significant $(p<0.05)$ indicated in bold.

Source

\section{A) Dependent $=$ Proportion of Species}

Particle Size*Feeding Guild

Heterogeneity*Feeding Guild

Particle Size*Heterogeneity*Feeding Guild

\section{B) Dependent $=$ Number of Individuals}

Particle Size*Feeding Guild

Heterogeneity*Feeding Guild

Particle Size*Heterogeneity*Feeding Guild df

F

$p$

$1 \quad 7.988$

0.481

0.006

1

1

0.497

0.490

0.483

1

2.784

0.100

1

2.162

0.146

1

0.909 


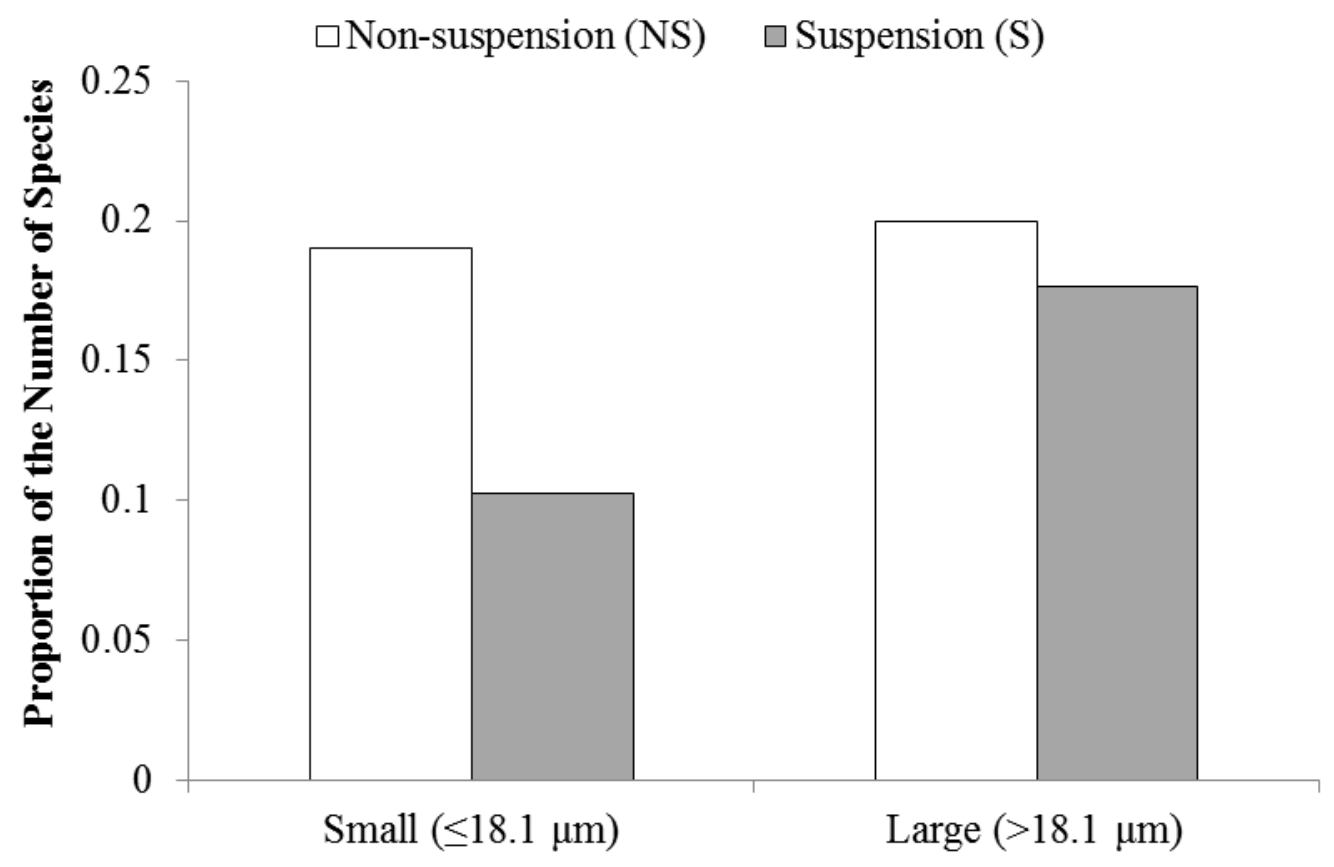

Particle Size Treatment

Figure 7: Significant particle size effect from a three-way ANOVA with independent variables: particle size (levels: small, large), and particle heterogeneity (levels: low, high), and feeding guild (non-suspension, suspension). Dependent variable is the proportion of species present within the benthic feeding guild assignment $(p=0.006)$ in Elkhorn Slough. Data were ranked for analysis and there are no appropriate confidence intervals for ranked data. 
Table 9: Three-way ANOVAs of the effects of particle size (levels: small, large) and particle heterogeneity (levels: low, high) on invertebrate benthic functional feeding guilds (deposit, non-deposit) in Elkhorn Slough for (A) the proportion of possible number of species in deposit or non-deposit guilds or (B) the rank number of individuals in deposit or non-deposit guilds. Error $\mathrm{df}=72$. Terms not including the feeding guild factor have no biological meaning for the analyses and have been excluded from this table.

Significant $(p<0.05)$ indicated in bold.

Source

df

A) Dependent= Proportion of Species

Particle Size*Feeding Guild

Heterogeneity*Feeding Guild

Particle Size*Heterogeneity*Feeding Guild

$1 \quad 10.782$

0.002

$1 \quad 0.352$

0.555

$\begin{array}{lll}1 & 0.532 & 0.468\end{array}$

B) Dependent $=$ Number of Individuals

Particle Size*Feeding Guild

$1 \quad 11.670$

0.001

Heterogeneity*Feeding Guild

1

$<0.001$

0.990

Particle Size*Heterogeneity*Feeding Guild

12.412

0.125 


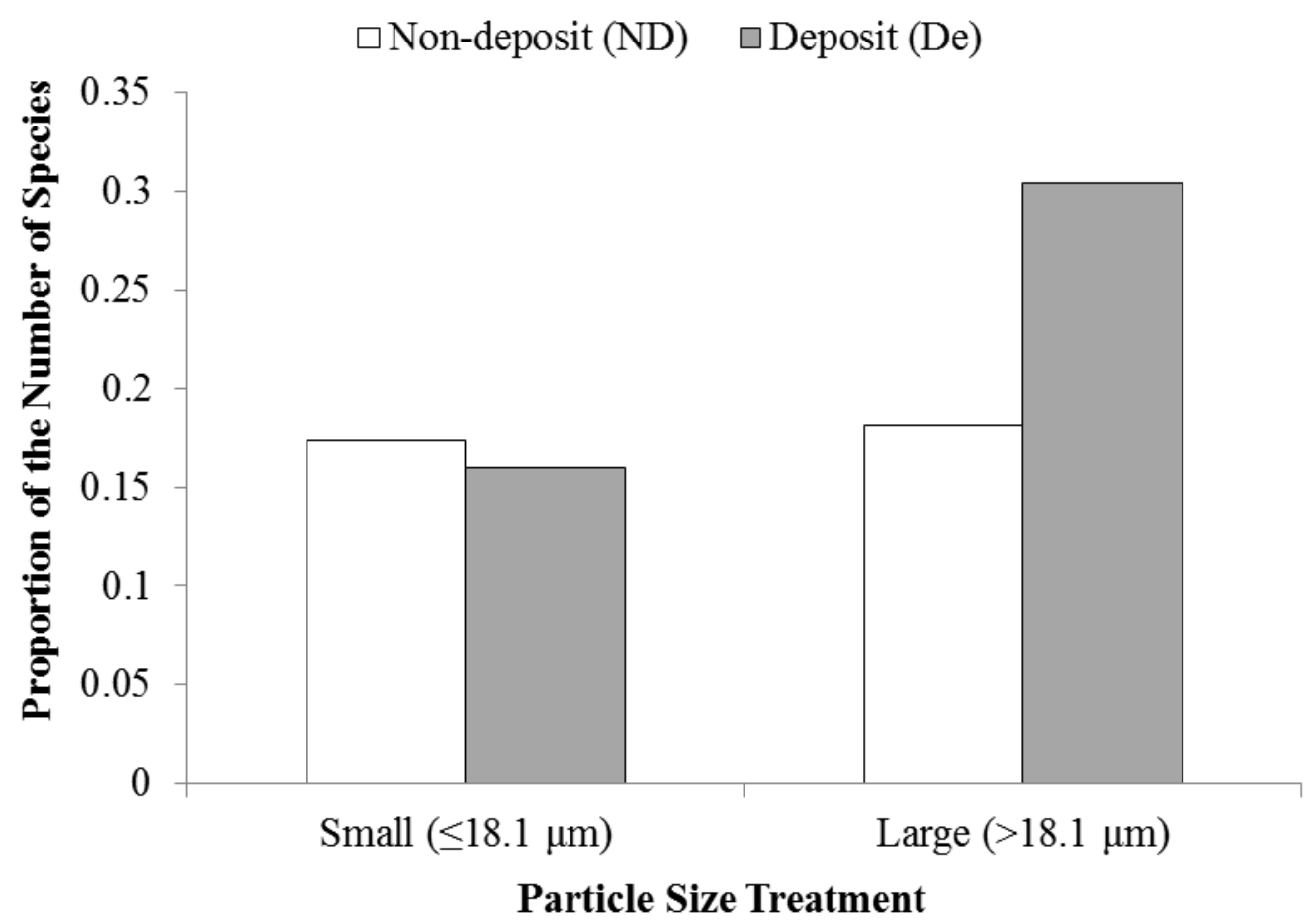

Figure 8: Significant particle size effect from a three-way ANOVA with independent variables: particle size (levels: small, large), and particle heterogeneity (levels: low, high), and feeding guild (non-deposit, deposit). Dependent variable is the proportion of species present within the benthic feeding guild assignment $(p=0.002)$ in Elkhorn Slough. Data were ranked for analysis and there are no appropriate confidence intervals for ranked data. 


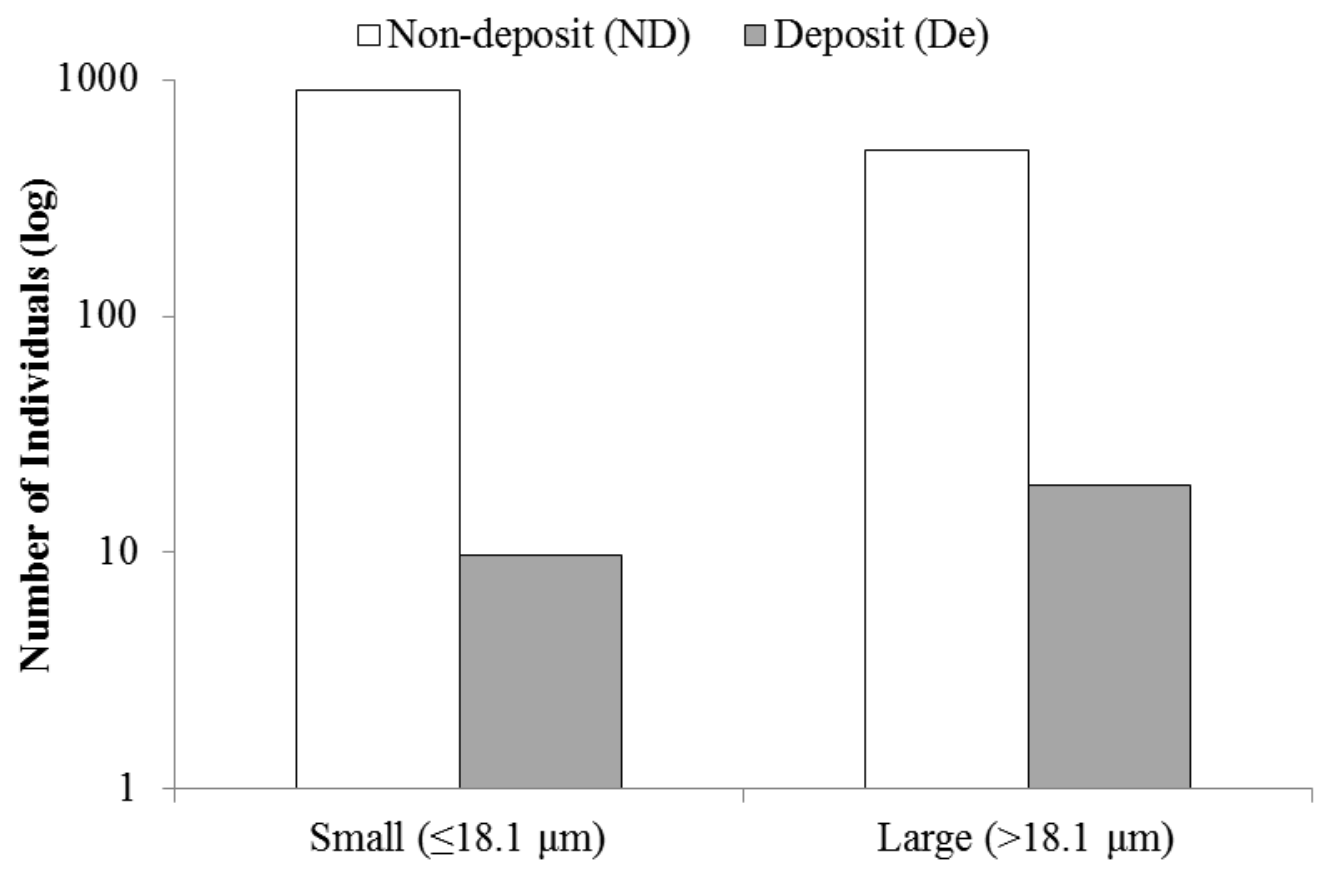

Particle Size Treatment

Figure 9: Significant particle size effect from a three-way ANOVA with independent variables: particle size (levels: small, large), and particle heterogeneity (levels: low, high), and feeding guild (non-deposit, deposit). Dependent variable is the log-scaled number of individuals present within the benthic feeding guild assignment $(p=0.001)$ in Elkhorn Slough. Data were ranked for analysis and there are no appropriate confidence intervals for ranked data.

\section{Discussion}

Any discussion of the results of community changes and particle size for this study of Elkhorn Slough needs to account for the four year lag between the benthic species survey and the sediment survey. Over time, particle size has increased, while particle heterogeneity has decreased (Philip Williams \& Associates Ltd., 1992; Malzonen 1999; Oliver et al., 2007). Unfortunately, there is no singular rate of erosion for the entirety of the slough (Reyes, 2009) so particle size and heterogeneity at any given site cannot be estimated for previous years with any degree of accuracy. It is possible that 
changes in the benthic community found within this study are a reflection of particle size and particle heterogeneity different than the 2007 sediment data. However, because sediment treatment classifications were reduced to only two categories, finding significant differences is more difficult (lower resolution) and any observed significant differences among the numbers of species and individuals within functional classifications of benthic species, with respect to sediment characteristics (particle size and particle heterogeneity), are likely to be true.

In this study, large particle size was associated with a lower number of surface species, along with a greater number of subsurface species (Figure 2). The lower number of surface-dwelling species and surface-dwelling individuals may be attributed to two factors. Visher (1969) has shown that increased particle size is positively associated with an increase of tidal exchange. Small surface-dwelling species that were less abundant or missing in the large particle size habitats (Figure 3), such as mobile polychaetes (e.g., Exogone lourei) or semi-mobile tube dwellers (e.g., Monocorophium ascherichim) may experience more difficulty in adhering to the substrate if water velocity is increased. Subsurface species, on the other hand, are protected from tidal forces by the sediment. Particle size was associated with a tradeoff between burrowing species and tubedwelling species (Figure 5). Burrowing species occurred only in areas of large particle sizes (Figure 4). This may be a function of burrowing time; it can take less time for certain species to burrow when particle size is large (Dugan, Hubbard, \& Lastra, 2000; Nel, McLachlan, \& Winter, 1999). Reduced burrowing time minimizes hydrodynamic forces exerted on the organism as well as exposure to surface predators (Dugan et al., 
2000). On the other hand, the tube building species dominated the benthic community in the small particle sized areas in Elkhorn Slough. Tube builders prefer smaller sediment sizes for tube construction (Krasnow \& Taghon, 1997; Prathep et al., 2003). It should be noted that in this research that the majority of tube-dwelling species were not suspension feeders (e.g., Leptochelia dubia). Particle size, therefore, had a significant effect on the community structure within Elkhorn Slough.

Feeding niche diversity was higher with higher particle heterogeneity (Figure 6). Bonsdorff and Pearson (1999) also found that functional groups were positively affected by habitat heterogeneity. When the heterogeneity of particles is high, there are more spatial niches for feeding guilds to occupy. The specimens collected during the survey were all macrofauna, suggesting the physical niches may not affect the feeding guilds themselves, but in fact affect the abundance and variety of the prey/food items (Tews et al., 2004; Alcorlo, Otero, \& Geiger, 2004). Barry, Yoklavich, Caillet, Ambrose, and Antrim (1996) also emphasized the importance of prey richness on trophic level distribution within marine habitats.

Differences in particle size were associated with differences in the representation of both suspension and deposit feeders (Figures 7, 8, 9). When particle size was large, there was a larger proportion of suspension feeder species. Suspension feeders prefer habitats with larger particle sizes as smaller particles have a tendency to clog their filtering machinery (Snelgrove \& Butman, 1994; Ellis, Cummings, Hewitt, Thrush, \& Norkko, 2002). Suspension feeders also rely on water currents to bring in fresh food supplies and there is a proportional increase in particle size when water flow velocity 
increases (Loudon \& Alstad 1990). The deposit feeding species of Elkhorn Slough also exhibited a preference for large particle sizes. Deposit feeders are very sensitive to particle size (Thrush et al., 2003) and will select habitats with particle sizes that can be easily passed through their gut (Ward \& Shumway, 2004).

This research indicates that the benthic community in Elkhorn Slough may change radically over time, particularly in response to changes in particle size. The tidal forces in the slough continue to increase in strength, and as a result, the particle size is increasing while particle heterogeneity is decreasing (Philip Williams \& Associates Ltd., 1992; Malzonen, 1999). The shift to a relatively large, homogenous particle size distribution will have a profound effect on species composition in the slough. If Elkhorn Slough continues to erode over time, the long-term result should be a decrease in the number of surface-dwelling species, a loss of surface and subsurface individuals, an increase in the number of domicile guilds, an increase in the number of tube-dwelling species, a decrease in the number of feeding guilds, an increase in the number of suspension species, and an increase in both the number of deposit feeding species and individuals.

Oliver et al. (2007) illustrated similar changes in a qualitative comparison of species data from a 1974-1976 Elkhorn Slough survey to a 2003 survey in the slough. For example, a new species, Nutricola tantilla, became dominant over the non-native Gemma gemma during the period when mean particle size increased. Nutricola tantilla is a subsurface, non-tube dwelling, suspension feeding species, all of which are functional groups positively affected by large particle sizes. Oliver et al. (2007) also noted the 
decrease in abundance of Streblospio benedicti, a surface and non-deposit feeding species.

Activities of benthic organisms can also exacerbate the effects of erosion on community structure. Erosion affects the distribution of benthic species, which affects the community structure, and interactions between species can maintain those changes. There is an amensalistic relationship between deposit feeders and suspension feeders (Snelgrove, 1999) that could contribute to the shift; bioturbation by deposit feeders causes suspension of fine particles which interferes with feeding efforts of suspension feeders (Rhoads \& Young, 1970). Suspension feeders are a crucial component of the benthic environment as they are biological mitigators; suspension feeders remove phytoplankton from the water column which suppresses organic matter and reduces eutrophication (Kirby \& Miller, 2005). Twenty-six percent of Elkhorn Slough's water stems from agricultural sources, which can cause eutrophication (Wankel, Mosier, Hansel, Payten, \& Francis, 2011). Benthic organisms can also impact community structure through habitat modification. There is a positive relationship between deposit feeder species and increasing particle size. The erosion within the slough will facilitate deposit feeders, who bioturbate the sediment with their feeding activity, which suspends fine particles, the first to be eroded via tidal forces (Masselink \& Hughes, 2003; McLusky \& Elliott, 2004). In essence, the interaction between deposit feeders and erosion is a positive feedback loop, accelerating the erosion process. Tube-dwellers are involved in a similar positive feedback loop. The constructed tubes of tube-dwelling species stabilize sediment (Fager, 1964). The tube-dwelling species of Elkhorn Slough, 
however, prefer to inhabit small particle-sized areas. The erosion in the slough will cause a decrease in tube-dwelling species, and the sediment will remain unstable and susceptible to erosive forces. 


\section{Works Cited}

Alcorlo, P., Otero, M., \& Geiger, W. (2004). Feeding preferences and food selection of the red swamp crayfish, Procambarus Clarkii, in habitats differing in food item diversity. Crustaceana, 77(4), 435-453. doi: 10.1163/1568540041643283

Barry, J., Yoklavich, M., Cailliet, G., Ambrose, D., \& Antrim, B. (1996). Trophic ecology of the dominant fishes in Elkhorn Slough, California, 1974-1980. Estuaries, 19(1), 115-138.

Blott, S.J., \& Pye, K. (2001). Gradistat: a grain size distribution and statistics package for the analysis of unconsolidated sediments. Earth Surface Processes and Landforms, 26, 1237-1248. doi: 10.1002/esp.261

Bonsdorff, E., \& Pearson, T.H. (1999). Variation in the sublittoral macrozoobenthos of the Baltic Sea along environmental gradients: A functional-group approach. Australian Journal of Ecology, 24, 312-326.

Botto, J., \& Iribarne, O. (2000). Contrasting effects of two burrowing crabs (Chasmagnathus granulata and Uca uruguayensis) on sediment composition and transport in estuarine environments. Estuarine, Coastal and Shelf Science, 51, 141-151. doi:10.1006/ecss.2000.0642

Crampton, T. A. (1994). Long term effects of Moss Landing Harbor on the wetlands of Elkhorn Slough (Unpublished M.S. Thesis). University of California Santa Cruz, Santa Cruz, CA.

Davis, J.R. (1980). Species composition and diversity of benthic macroinvertebrates in the upper Rio Grande, Texas. The Southwestern Naturalist, 25(20), 137-150.

Downes, B. J., Lake, P., Schreiber, E., \& Glaister, A. (1998). Habitat structure and regulation of local species diversity in a stony, upland stream. Ecological Monographs, 68(2), 237-257.

Downes, B. J., Lake, P. S., Glaister, A., \& Bond, N. R. (2006). Effects of sand sedimentation on macroinvertebrate fauna of lowland streams: are the effects consistent? Freshwater Biology, 51, 144-160. 
Dugan, J.E., Hubbard, D.M., \& Lastra, M. (2000). Burrowing abilities and swash behavior of three crabs, Emerita analoga Stimpson, Blepharipoda occidentalis Randall and Lepidopa californica Efford (Anomura, Hippoidea), of exposed sandy beaches. Journal of Experimental Marine Biology and Ecology, 255(2), 229-245.

Ellingsen, K.E. (2002). Soft-sediment benthic biodiversity on the continental shelf in relation to environmental variability. Marine Ecology Progress Series, 232, 1527.

Ellis, J., Cummings, V., Hewitt, J., Thrush, S., \& Norkko, A. (2002). Determining effects of suspended sediment on condition of a suspension feeding bivalve (Atrina zelandica): results of a survey, a laboratory experiment and a field transplant experiment. Journal of Experimental Marine Biology and Ecology, 267, 147-174.

Etter, R. J., \& Grassle, J. F. (1992). Patterns of species diversity in the deep sea as a function of sediment particle size diversity. Nature, 360, 576-578.

Fager, E. W. (1964). Marine sediments: Effects of a tube-building polychaete. Science (New York, N.Y.), 143(3604), 356-358. doi:143/3604/356

Gray, J. S. (2002). Species richness of marine soft sediments. Marine Ecology Progress Series, 244, 285-297.

Huston, M. (1979). A general hypothesis of species diversity. American Naturalist, 113(1), 81-101.

Johnson, R. G. (1970). Variations in diversity within benthic marine communities. American Naturalist, 104(937), 285-300.

Kirby, M. X., \& Miller, H. M. (2005). Response of a benthic suspension feeder (Crassostrea virginica Gmelin) to three centuries of anthropogenic eutrophication in Chesapeake Bay. Estuarine, Coastal and Shelf Science, 62(2005), 679-689. doi:10.1016/j.ecss.2004.10.004

Krasnow, L. D., \& Taghon, G. L. (1997). Rate of tube building and sediment particle size selection during tube construction by the Tanaid crustacean, Leptochelia dubia. Estuaries, 20(3), 534-546.

Loudon, C., \& Alstad, D. N. (1990). Theoretical mechanics of particle capture: predictions for Hydropsychid caddisfly distributional ecology. American Naturalist, 135(3), 360-381. 
Macdonald, T.A., Burd, B.J., Macdonald, V.I., \& van Roodselaar, A. (2010). Taxonomic and feeding guild classification for the marine benthic macroinvertebrates of the Strait of Georgia, British Columbia. Sidney, BC: Canadian Technical Report of Fisheries and Aquatic Sciences 2874.

Malzonen, C. M. (1999). Tidal scour and its relation to erosion and sediment transport in Elkhorn Slough. (M.S. thesis). Retrieved from SJSU ScholarWorks. (1826)

Masselink, G., \& Hughes, M. G. (2003). Introduction to coastal processes and geomorphology. New York, NY.

McLusky, D. S., \& Elliott M. (2004). The estuarine ecosystem: ecology threats and management $\left(3^{\text {rd }}\right.$ ed.). New York, NY: Oxford University Press.

Nel, R., McLachlan, A., \& Winter, D. (1999). The effect of sand particle size on the burrowing ability of the beach Mysid Gastrosaccus psammodytes Tattersall.

Estuarine, Coastal and Shelf Science, 48, 599-604.

Oliver, J.S., Hammerstrom, K.K., Kim, S.L, Slattery, P.N., Oakden, J.A., Kvitek, R.A., \& Aiello, I.W. (2007). Characterization of the Benthic and Planktonic Communities of Elkhorn Slough. Monterey, CA: Monterey Bay National Estuarine Sanctuary Integrated Monitoring Network (SIMoN).

Philip Williams \& Associates, Ltd. (1992). Elkhorn Slough tidal hydraulics erosion study. San Francisco, CA: U.S. Army Corps of Engineers San Francisco District.

Prathep, A., Marrs, R., \& Norton, T. (2003). Spatial and temporal variations in sediment accumulation in an algal turf and their impact on associated fauna. Marine Biology, 142(2), 381-390.

Reyes, C. E. (2009). Effects of erosion on the distribution of subtidal communities in Elkhorn Slough, Monterey County; California. (Unpublished M.S. thesis). California State University Fresno, Fresno, CA.

Rhoads, D. C., \& Young, D. K. (1970). The influence of deposit-feeding organisms on sediment stability and community trophic structure. Journal of Marine Research, 28(2), 150-178.

Riddle, M. J. (1988). Patterns in the distribution of macrofaunal communities in coral reef sediments on the central Great Barrier Reef. Marine Ecology Progress Series, 47(3), 281-292. 
Sebens, K. P. (1991). Habitat structure and community dynamics in marine benthic systems. In: E. D. McCoy, S. A. Bell \& H. Mushinsky (Eds.), Habitat Structure: the Physical Arrangement of Objects in Space (211 - 234). London: Chapman and Hall.

Simpson, G. G. (1964). Species density of North American recent mammals. Systematic Zoology, 13(2), 57-73.

Snelgrove, P. V. (1999). The biodiversity of macrofaunal organisms in marine sediments. Biodiversity \& Conservation, 7(9), 1123-1132.

Snelgrove, P. V., \& Butman, C. A. (1994). Animal-sediment relationships revisited: cause versus effect. Oceanography and Marine Biology: An Annual Review, 32, 11-177.

Tews, J., Brose, U., Grimm, V., Tielbörger, K., Wichmann, M., Schwager, M., \& Jeltsch, F. (2004). Animal species diversity driven by habitat heterogeneity/diversity: the importance of keystone structures. Journal of Biogeography, 31(1), 79-92.

Thrush, S. F., Hewitt, J. E., Norkko, A., Nicholls, P. E., Funnell, G. A., \& Ellis, J. I. (2003). Habitat change in estuaries: predicting broad-scale responses of intertidal macrofauna to sediment mud content. Marine Ecology Progress Series, 263, 101112.

Vanaverbeke, J., Merckx, B., Degraer, S., \& Vincx, M. (2011). Sediment-related distribution patterns of nematodes and macrofauna: Two sides of the benthic coin? Marine Environmental Research, 71(1), 31-40.

Visher, G. S. (1969). Grain size distributions and deposititonal processes. Journal of Sedimentary Petrology, 39(3), 1074-1106.

Wankel, S. D., Mosier, A. C., Hansel, C. M., Payten, A., \& Francis, C. A. (2011). Spatial variability in nitrification rates and ammonia-oxidizing microbial communities in the agriculturally impacted Elkhorn Slough Estuary, California. Applied and Environmental Microbiology, 77(1), 269-280. doi:10.1128/AEM.01318-10

Ward, J. E., \& Shumway, S. E. (2004). Separating the grain from the chaff: Particle selection in suspension- and deposit-feeding bivalves. Journal of Experimental Marine Biology and Ecology, 300, 83-130. doi:10.1016/j.jembe.2004.03.002

Waters, T. F. (1995). Sediment in Streams Sources, Biological Effects and Control. Maryland, USA: American Fisheries Society. 
Wyżga, B., Oglęcki, P., Radecki-Pawlik, A., Skalski, T., \& Zawiejska, J. (2012). Hydromorphological complexity as a driver of the diversity of benthic invertebrate communities in the Czerny Dunajec River, polish Carpathians. Hydrobiologia, 696(1), 29-46.

Zar, J. H. (2010). Biostatistical analysis (5th ed.). Upper Saddle River, NJ: Pearson Prentice-Hall.

Zilli, F. L., Montalto, L., \& Marchese, M. R. (2008). Benthic invertebrate assemblages and functional feeding groups in the Paraná River floodplain (Argentina). Limnologica-Ecology and Management of Inland Waters, 38(2), 159-171. 


\begin{tabular}{|c|c|c|c|c|c|c|c|c|c|c|c|}
\hline \multirow{5}{*}{ 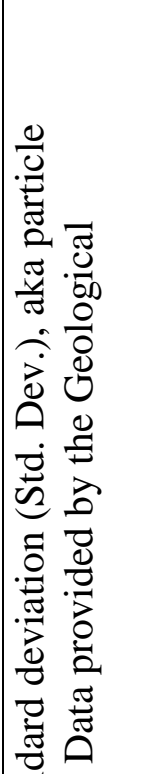 } & 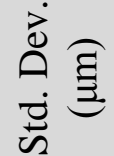 & Sิ & $\ddot{n}$ & $\underset{\nabla}{F}$ & $\begin{array}{l}\text { ț } \\
\stackrel{+}{*}\end{array}$ & $\underset{\sim}{\stackrel{f}{*}}$ & ñ & $\underset{\dot{\sigma}}{\dot{t}}$ & $\stackrel{\text { }}{m}$ & $\begin{array}{l}\ddagger \\
\infty \\
i\end{array}$ & $\vec{n}$ \\
\hline & 总高 & $\begin{array}{l}\infty \\
\infty \\
\infty \\
\infty\end{array}$ & $\stackrel{\infty}{=}$ & $\ddot{\stackrel{\leftrightarrow}{8}}$ & $\stackrel{\stackrel{N}{N}}{\sim}$ & ֶָ. & nn & $\vec{\infty}$ & $\ddot{\ddot{g}}$ & ले & 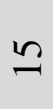 \\
\hline & : & లె & m & m & $\stackrel{n}{m}$ & li & $\bar{m}$ & $\stackrel{\infty}{n}$ & ले & 우 & $\bar{\gamma}$ \\
\hline & 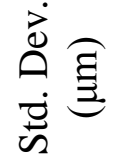 & $\begin{array}{l}\infty \\
n \\
m \\
m\end{array}$ & ते & $\stackrel{n}{\sim}$ & तે & $\stackrel{\sim}{\sim}$ & $\stackrel{\infty}{\vec{r}}$ & $\underset{\sim}{\stackrel{J}{*}}$ & \begin{tabular}{l}
\multirow{2}{*}{.} \\
ஸे.
\end{tabular} & $\underset{\vec{r}}{\partial}$ & $\frac{\vartheta}{m}$ \\
\hline & $\stackrel{\sqrt[N]{\mathrm{g}}}{\mathrm{g}}$ & $\begin{array}{l}\infty \\
\infty \\
\infty\end{array}$ & $\begin{array}{l}n \\
\infty \\
\infty \\
\infty\end{array}$ & $\hat{\imath}$ & ב̀ & 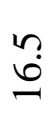 & $\stackrel{n}{ \pm}$ & $\begin{array}{l}\infty \\
\stackrel{\sim}{\sim}\end{array}$ & $\stackrel{\infty}{\stackrel{\sim}{I}}$ & $\stackrel{\Upsilon}{\circ}$ & $\frac{t}{a}$ \\
\hline 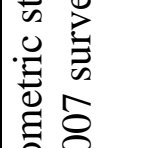 & 䔍 & N & $\ddot{\lambda}$ & $\underset{\sim}{\Delta}$ & $\stackrel{\sim}{d}$ & $\underset{\sim}{ }$ & $\hat{\imath}$ & $\stackrel{\infty}{\sim}$ & ते & లి & $\bar{m}$ \\
\hline 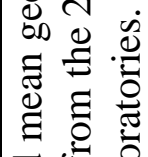 & 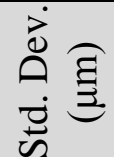 & $\underset{i}{\stackrel{7}{+}}$ & $\begin{array}{l}\infty \\
\dot{\infty} \\
\dot{m}\end{array}$ & $\begin{array}{l}\infty \\
\stackrel{\infty}{\circ} \\
\text {. }\end{array}$ & $\stackrel{n}{m}$ & $\begin{array}{l}\infty \\
\infty \\
\dot{\sim}\end{array}$ & ले & भे & $\underset{+}{\sim}$ & $\stackrel{\infty}{\circ}$ & $\underset{\sim}{\stackrel{N}{n}}$ \\
\hline 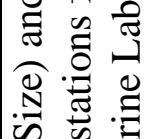 & 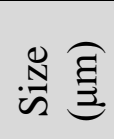 & $\stackrel{\vartheta}{i}$ & $\stackrel{n}{\exists}$ & in & $\stackrel{\infty}{0}$ & $\stackrel{\vartheta}{\dot{\infty}}$ & $\frac{m}{m}$ & $\stackrel{\nabla}{\stackrel{\Xi}{\Delta}}$ & $\stackrel{\searrow}{ \pm}$ & $\begin{array}{l}\stackrel{0}{\sim} \\
\stackrel{\sim}{N}\end{array}$ & $\begin{array}{l}n \\
\ddot{q}\end{array}$ \\
\hline 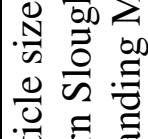 & . & $\simeq$ & $\stackrel{m}{-}$ & \pm & 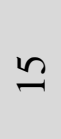 & 0 & $I$ & $\stackrel{\infty}{.}$ & 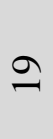 & ণ & $\vec{\sim}$ \\
\hline 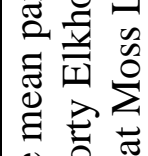 & 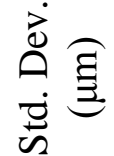 & 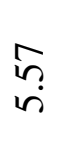 & 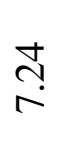 & $\stackrel{\infty}{\sim}$ & $\stackrel{m}{\rightleftarrows}$ & $\underset{F}{\ni}$ & $\begin{array}{l}\widetilde{\sigma} \\
+ \\
+\end{array}$ & तु? & $\underset{\nabla}{\nabla}$ & $\stackrel{乛}{\stackrel{r}{+}}$ & 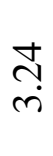 \\
\hline 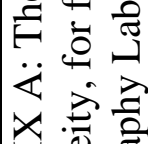 & 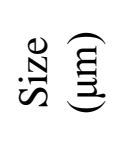 & 8 & $\stackrel{0}{8}$ & $\varrho$ & $\widetilde{\sigma}$ & & $\begin{array}{l}n \\
\infty \\
\infty\end{array}$ & هु. & $\stackrel{\infty}{\stackrel{0}{0}}$ & $\dot{\vec{\lambda}}$ & 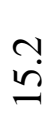 \\
\hline 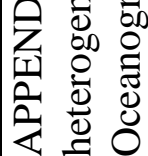 & 总 & - & $N$ & $m$ & $\nabla$ & in & 0 & $\infty$ & $a$ & 은 & $\Xi$ \\
\hline
\end{tabular}




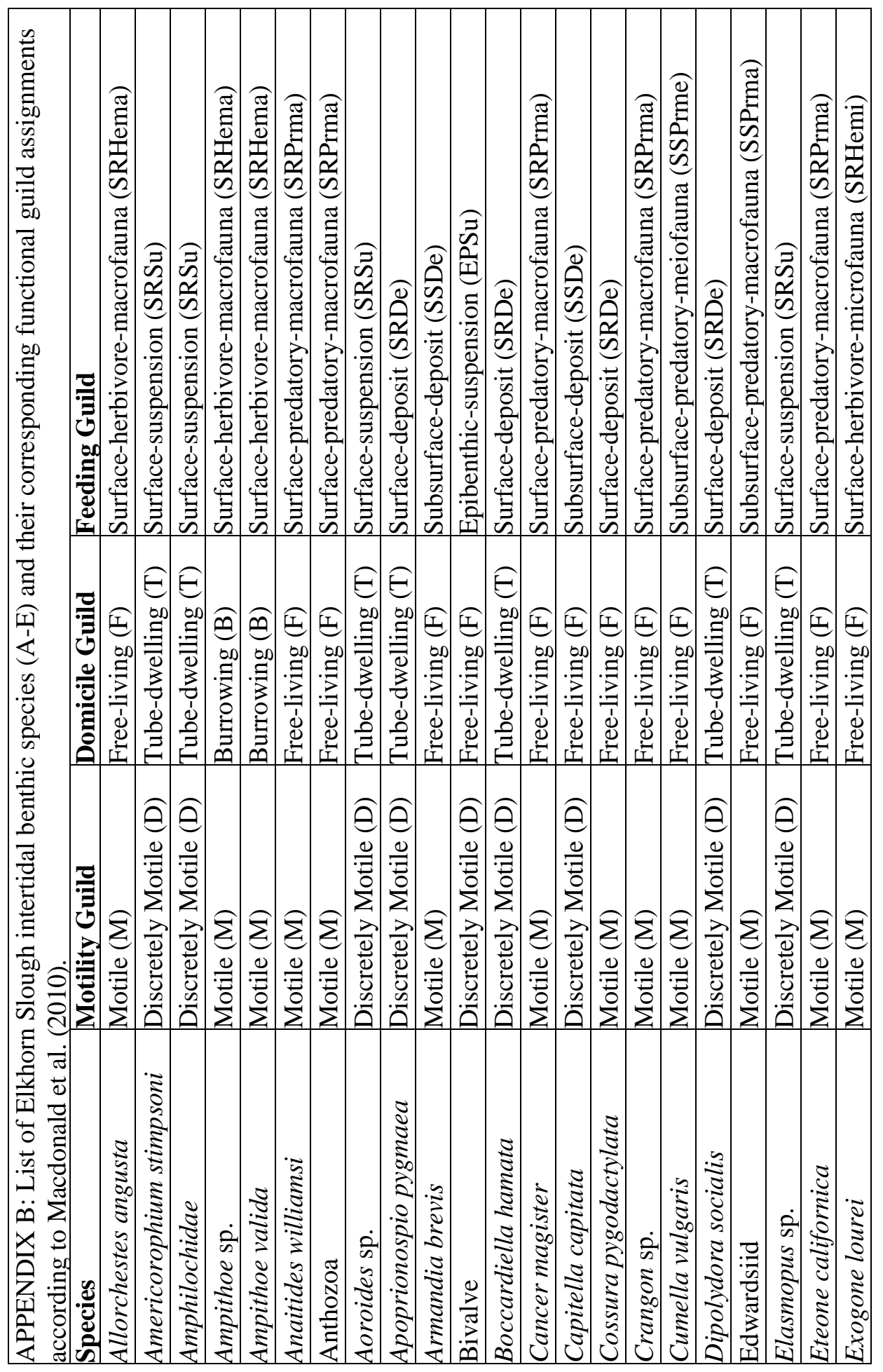




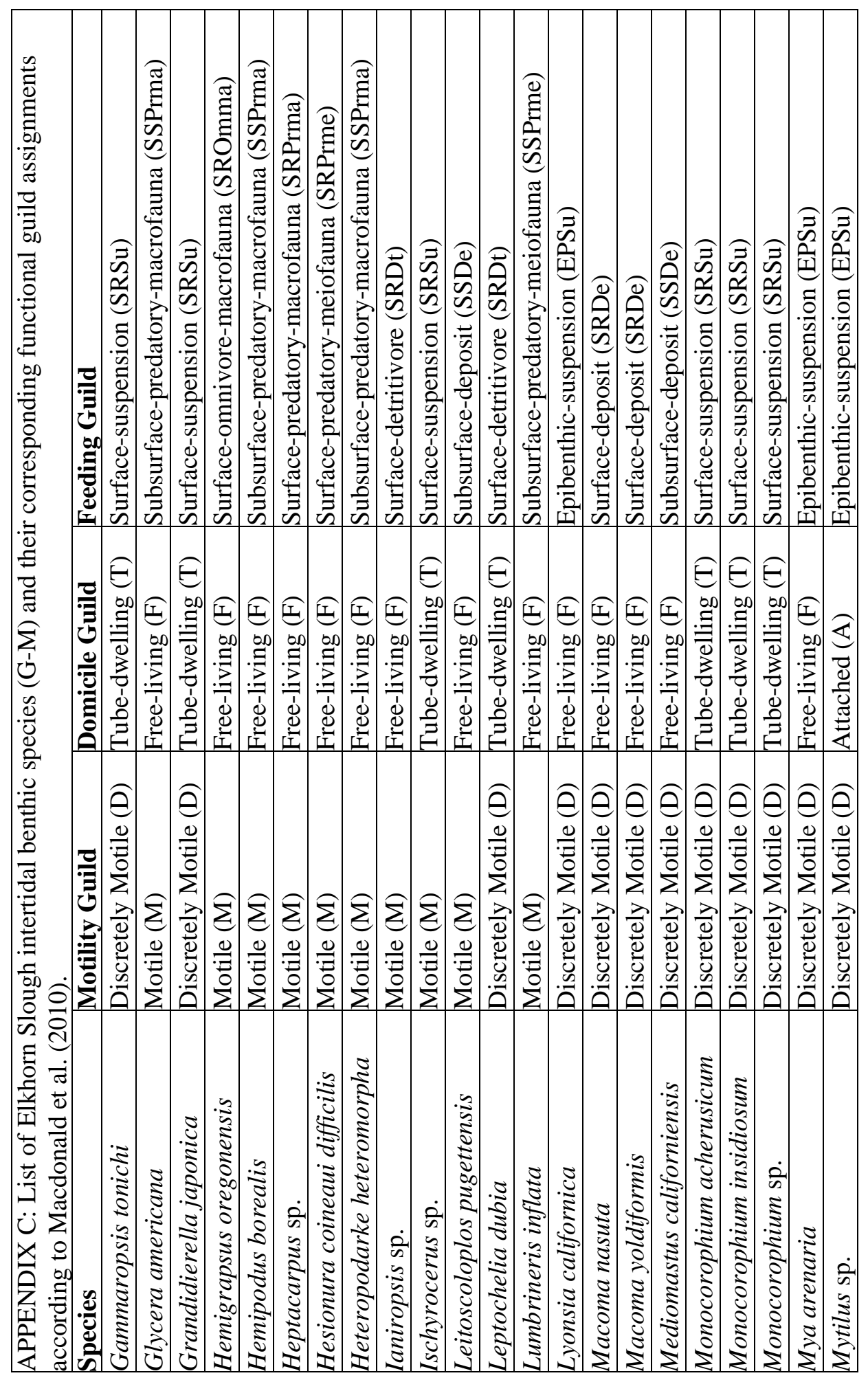




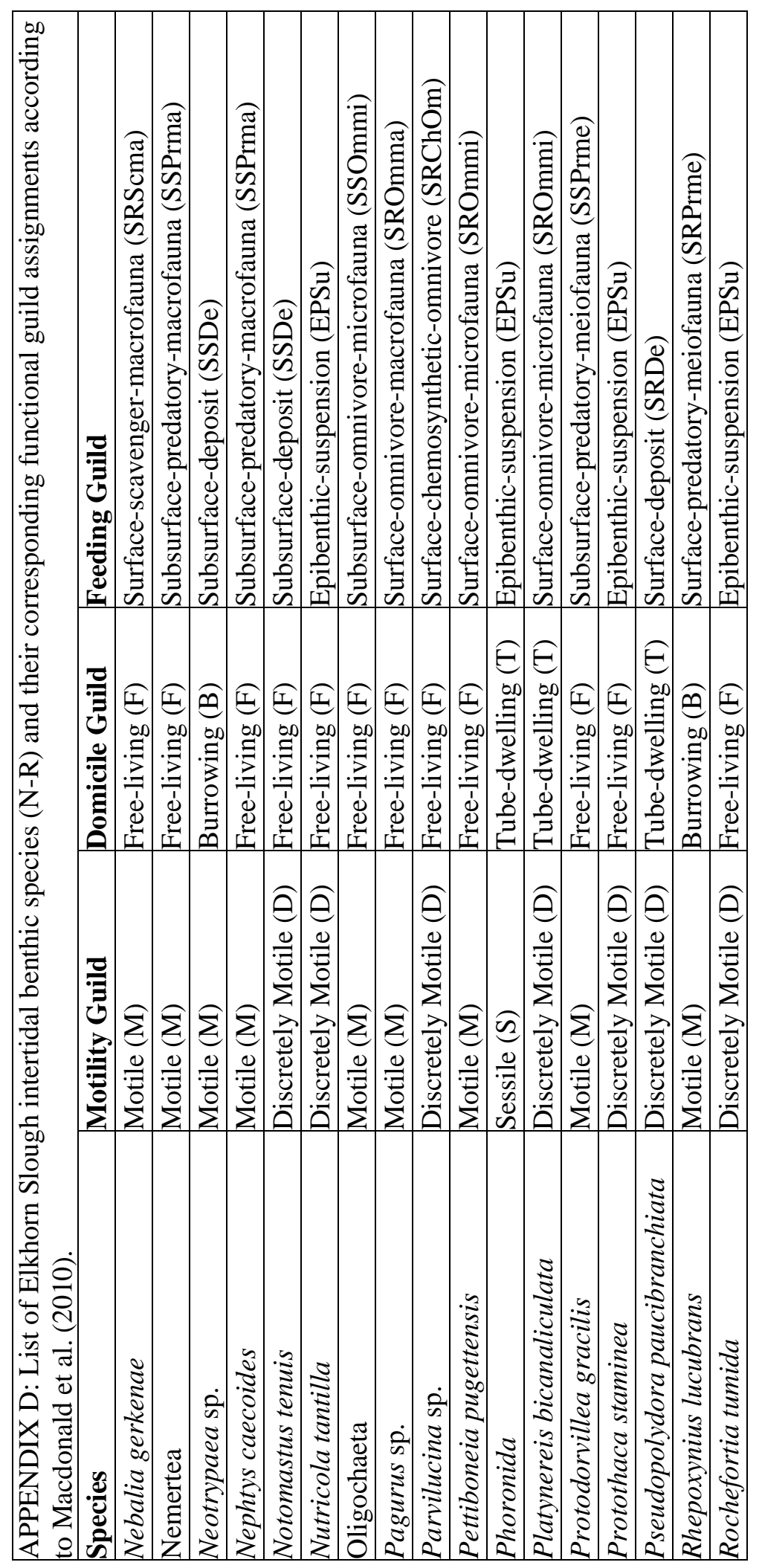




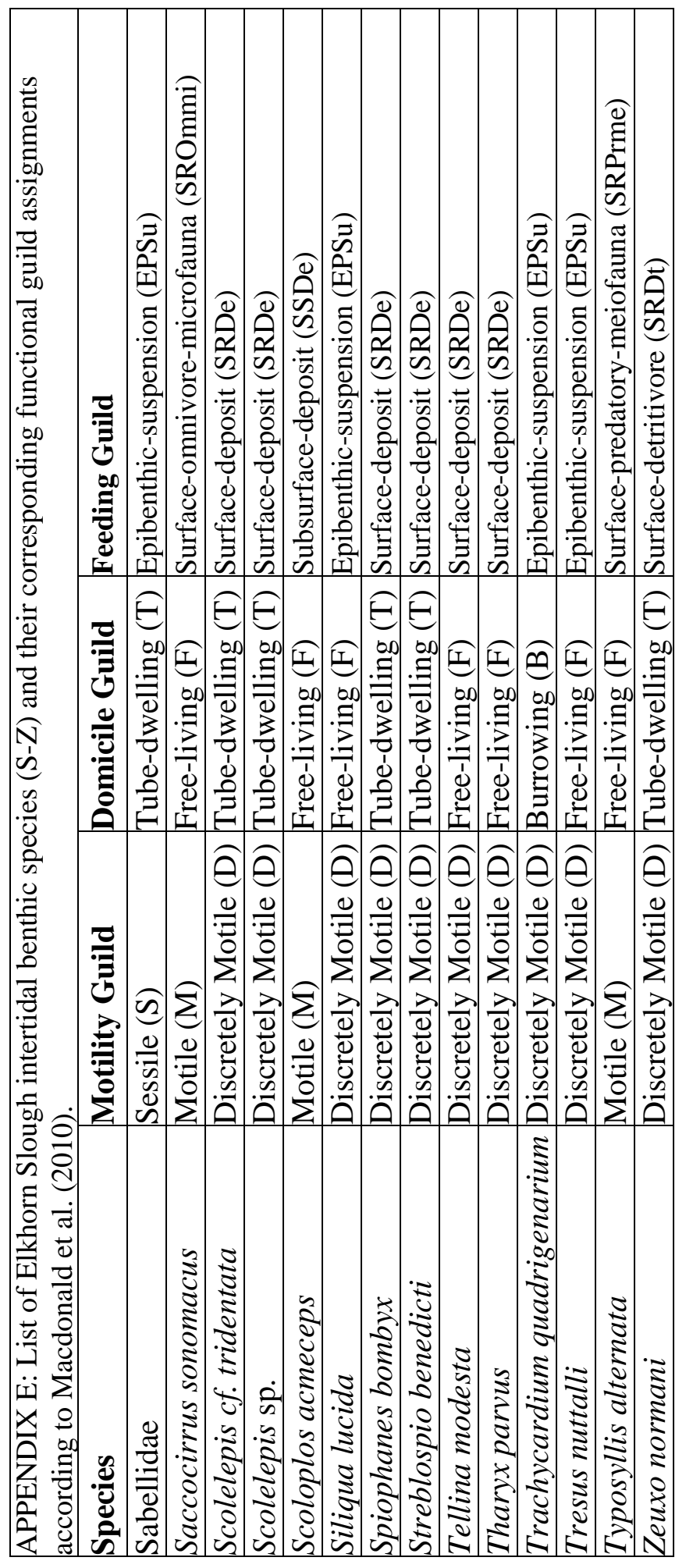




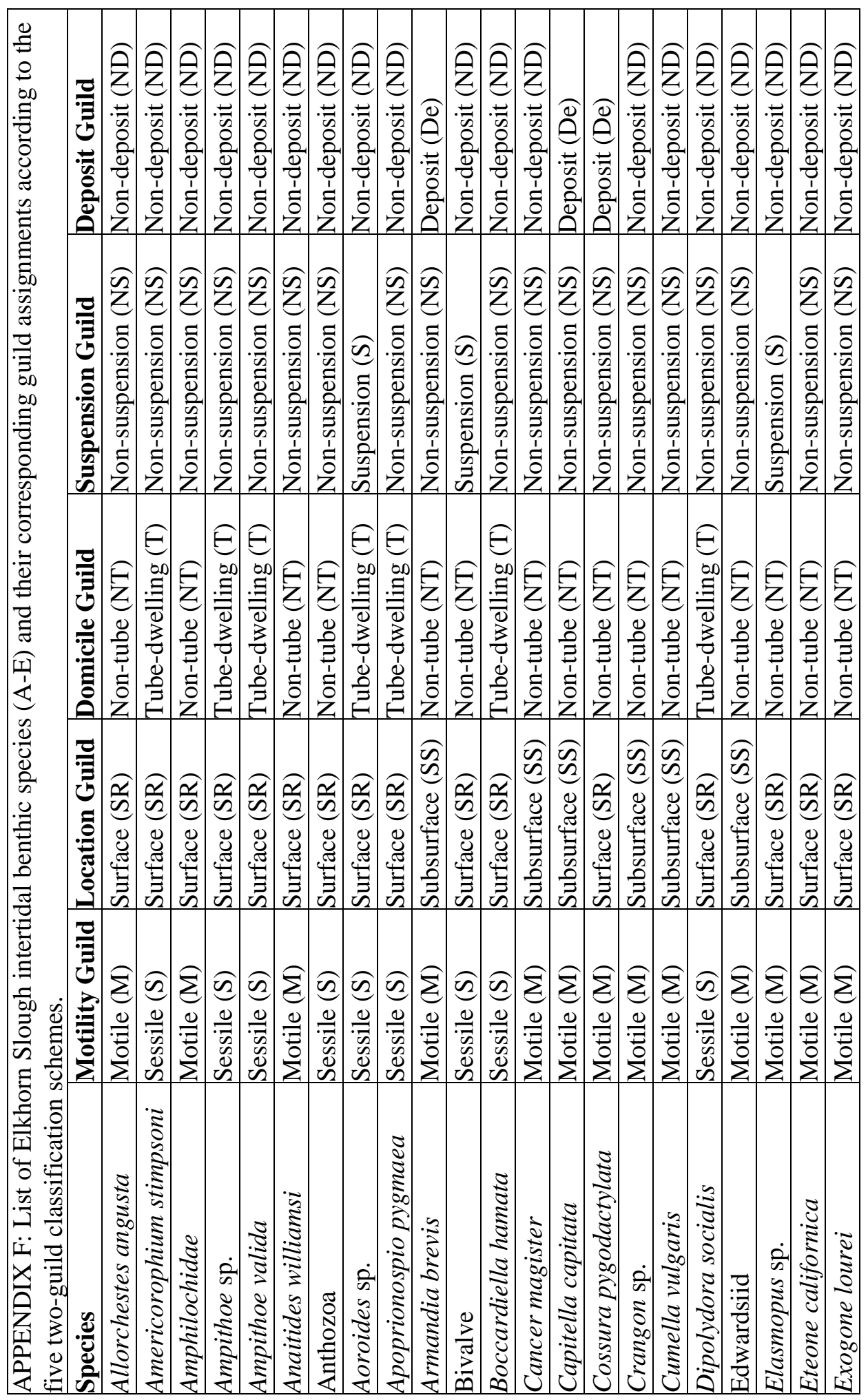




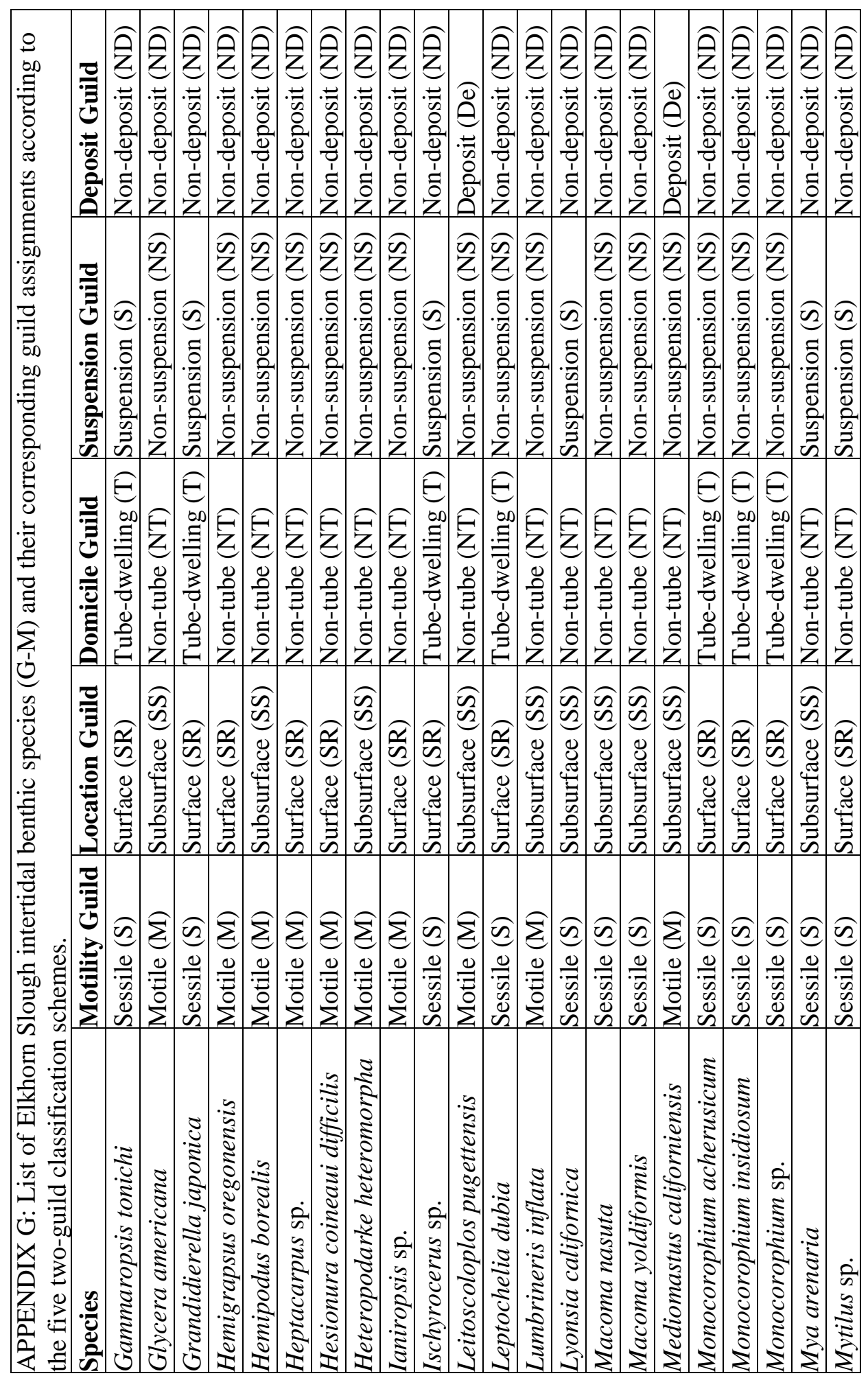




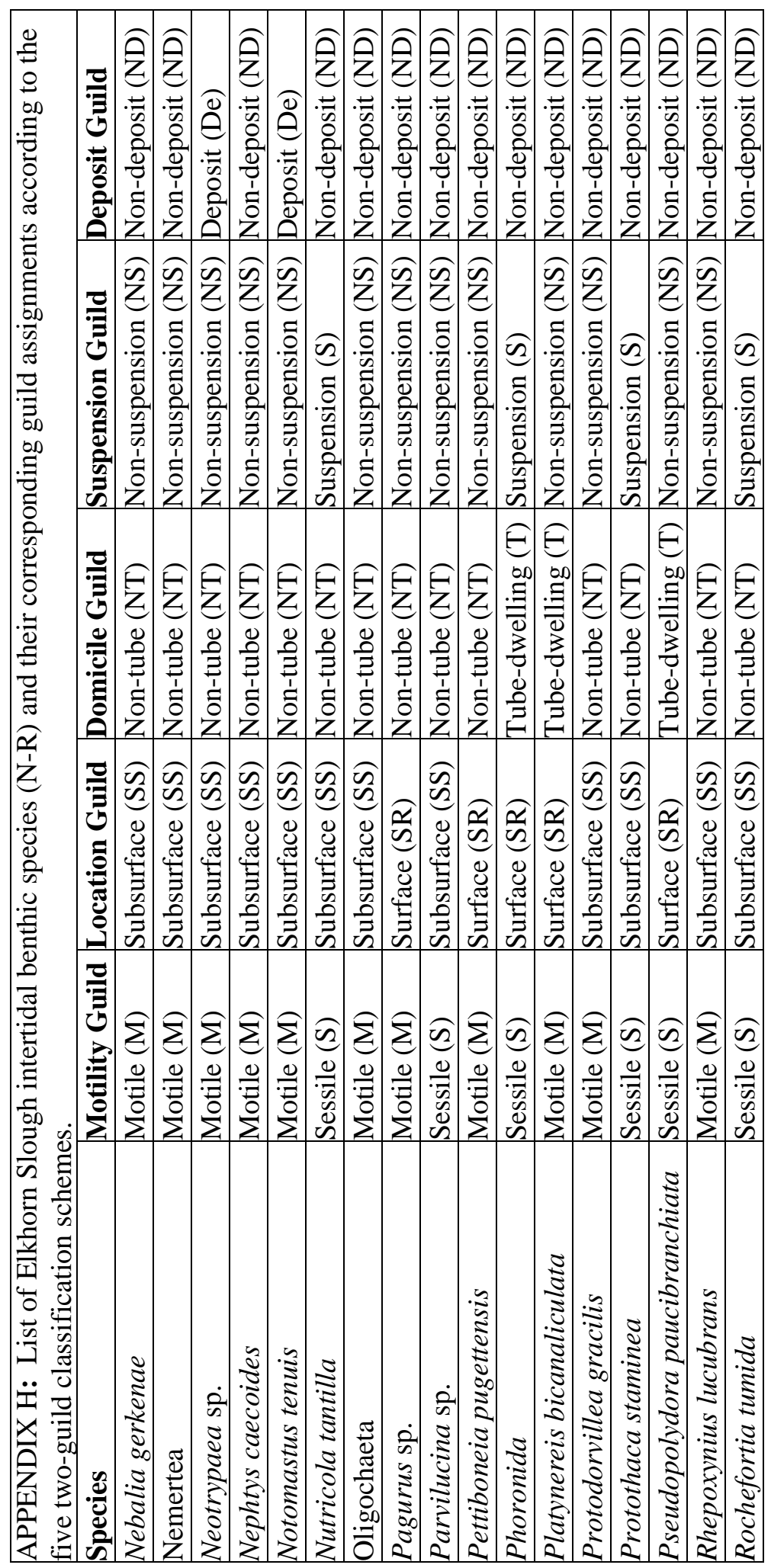




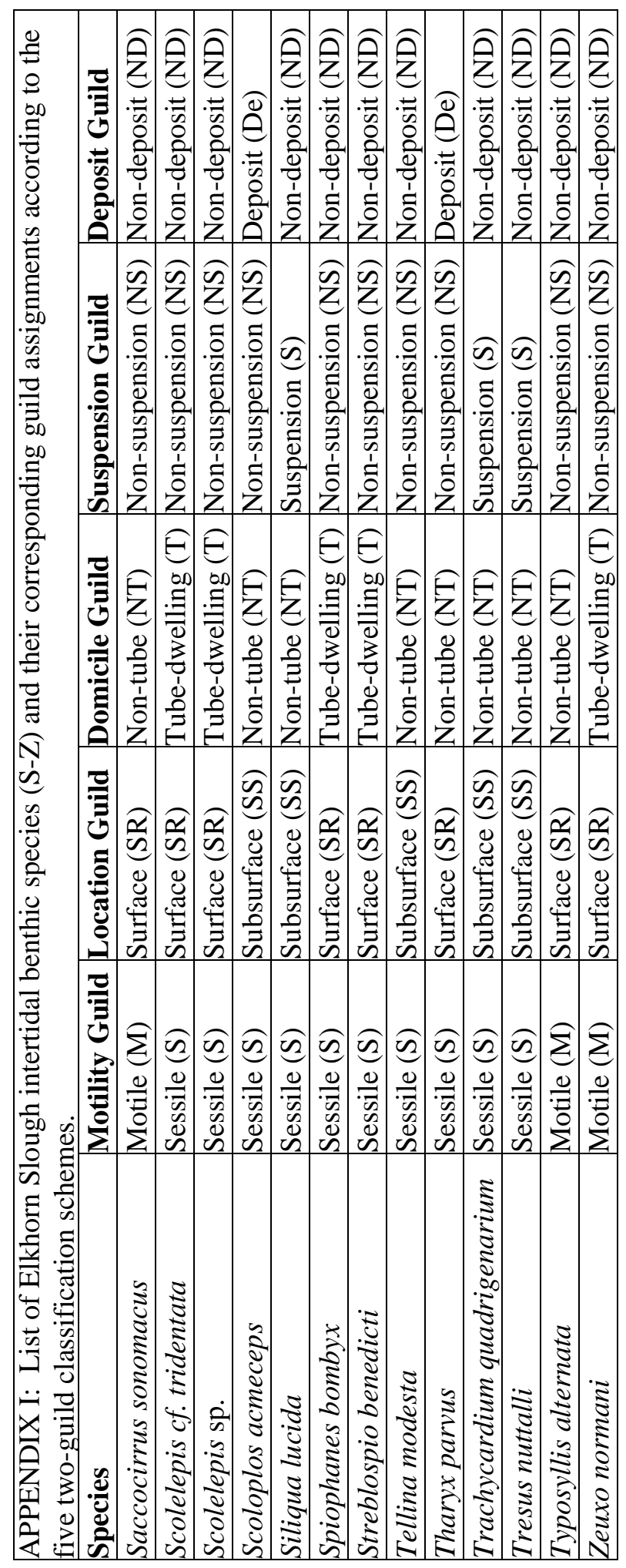




\begin{tabular}{|c|c|c|}
\hline \multirow{2}{*}{ Burrowing (B) Species Abundance } & \multicolumn{2}{|c|}{ Particle Size } \\
\hline & Small & Large \\
\hline Ampithoe sp. & 0 & 1 \\
\hline Neotrypaea sp. & 0 & 3 \\
\hline Rhepoxynius lucubrans & 0 & 1 \\
\hline Trachycardium quadrigenarium & 0 & 4 \\
\hline
\end{tabular}

\begin{tabular}{|l|c|c|}
\hline \multirow{2}{*}{$\begin{array}{l}\text { APPENDIX K: The number of species within the sixteen Elkhorn Slough benthic } \\
\text { invertebrate feeding guilds among the particle heterogeneity treatments. }\end{array}$} \\
\hline \multirow{3}{*}{ Feeding Guild } & \multicolumn{2}{|c|}{ Particle Heterogeneity } \\
\cline { 2 - 3 } & $\begin{array}{c}\text { Low } \\
(\leq 4.175 \mu \mathrm{m})\end{array}$ & $\begin{array}{c}\text { High } \\
(>4.175 \mu \mathrm{m})\end{array}$ \\
\hline Epibenthic-suspension (EPSu) & 24 & 44 \\
\hline Subsurface-deposit (SSDe) & 24 & 49 \\
\hline Subsurface-omnivore-microfauna (SSOmmi) & 17 & 19 \\
\hline Subsurface-predatory-macrofauna (SSPrma) & 21 & 29 \\
\hline Subsurface-predatory-meiofauna (SSPrme) & 5 & 19 \\
\hline Surface-chemosynthetic-omnivore (SRChOm) & 0 & 1 \\
\hline Surface-deposit (SRDe) & 39 & 57 \\
\hline Surface-detritivore (SRDt) & 17 & 24 \\
\hline Surface-herbivore-macrofauna (SRHema) & 8 & 8 \\
\hline Surface-herbivore-microfauna (SRHemi) & 15 & 21 \\
\hline Surface-omnivore-macrofauna (SROmma) & 1 & 3 \\
\hline Surface-omnivore-microfauna (SROmmi) & 5 & 10 \\
\hline Surface-predatory-macrofauna (SRPrma) & 6 & 13 \\
\hline Surface-predatory-meiofauna (SRPrme) & 0 & 3 \\
\hline Surface-scavenger-macrofauna (SRScma) & 0 & 2 \\
\hline Surface-suspension (SRSu) & 37 & 23 \\
\hline
\end{tabular}

